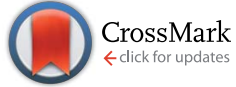

Cite this: RSC Adv., 2017, 7, 17044

Received 1st January 2017

Accepted 27th February 2017

DOI: $10.1039 / c 7 r a 00002 b$

rsc.li/rsc-advances

\section{Current status of electron transport layers in perovskite solar cells: materials and properties}

\author{
Khalid Mahmood, ${ }^{* a}$ Saad Sarwar ${ }^{\mathrm{b}}$ and Muhammad Taqi Mehran ${ }^{\mathrm{b}}$
}

Methyl ammonium lead halide-based hybrid perovskite solar cells (PSCs) have been intensively studied in recent years because of their high efficiency and low processing costs. Although there are limited constraints for choosing the planar electron transport layer (ETL) or mesoscale electron transporting material (ETM), a great deal of effort is required in designing complex nanostructures which are effective as ETL/ETM to achieve high open circuit voltage $\left(V_{\text {oc }}\right)$ and high fill factor (FF) in PSCs. In this review, various inorganic and organic ETLs, as well as inorganic ETM systems, used for PSCs are summarized. The transport mechanism of electrons in these different ETL/ETM materials is discussed along with their effect on $V_{\text {oc }}$ on the basis of energy band diagrams with respect to the perovskite absorber. The authors also discuss the microstructure/nanostructure aspect of mesoscopic ETMs, doping and surface functionalization, and the influence of these parameters on solar cell behaviour, performance, and hysteresis effects. The authors also discussed the microstructure/nanostructure aspect of ETL on shape of current density vs. voltage $(J-V)$ hysteresis in this review. Technical issues and recent progress of ETL to improve device efficiency and stability in terms of materials, process, and characterization are summarized.

\section{Introduction}

The hybrid nature (inorganic and organic) of perovskite materials ${ }^{1}$ facilitates their use in devices such as solar cells, ${ }^{2}$ light emitting diodes, ${ }^{3,4}$ photodetectors, ${ }^{5-8}$ ferroelectric devices, and ferromagnetic devices. ${ }^{9}$ A hybrid perovskite $\left(\mathrm{RMX}_{3}\right.$ where $\mathrm{R}$ : alkyl, A: ammonium, M: metal and X: halogen) solar cell has the potential to offer low-cost solar energy conversion and can be fabricated on glass and flexible substrates. ${ }^{\mathbf{1 0 - 1 8}}$ In particular, methyl (M) ammonium ( $\mathrm{NH}^{3+}$ ) metal ( $\mathrm{Sn}, \mathrm{Pb}$ and $\mathrm{Eu}$ ) halide (Cl, $\mathrm{Br}$ and $\mathrm{I}$ ) is suitable for solar cells because of its optimum band gap (1.3-2.9 eV), ${ }^{8-12}$ and its band gap can be tuned with different metal ions and halide cations, as well as different metal doping to its backbone. ${ }^{19-22}$ For example, use of formamidinium (FA) rather than methyl ammonium lowers the band gap; with the absorption band tail eventually exceeding $800 \mathrm{~nm} .^{23,24}$ This versatile material also has a higher exciton diffusion length $(1000 \mathrm{~nm})$ and lower exciton binding energy with broad spectral absorption and visible emission providing more room for device researchers to explore the physics behind the perovskite solar cell (PSC). ${ }^{25-29}$ A hybrid PSC can achieve efficiency as high as $20 \%$ within a short period of time. ${ }^{30}$ This peculiar material has triggered extensive study into material and fundamental

${ }^{a}$ Department of Chemical \& Polymer Engineering, University of Engineering \& Technology Lahore, Faisalabad Campus, $3 \frac{1}{2}$ Km. Khurrianwala-Makkuana By-Pass, Faisalabad, Pakistan. E-mail: khalid@kaist.ac.kr

${ }^{b}$ University of Science and Technology (UST), 217-Gajeong-ro, Yuseong-gu, Daejeon, 34113, Republic of Korea physics for next generation solar cell materials because of the variety of fabrication techniques and exceptional optoelectronic properties. It is hoped that the efficiency will exceed that of crystalline silicon solar cells in the near future. Effective masses of photogenerated electrons and holes have been estimated as $m_{\mathrm{e}}{ }^{*}=0.23 m_{0}$ and $m_{\mathrm{h}}{ }^{*}=0.29 m_{0}$, respectively, including spinorbit coupling effects. ${ }^{20,31,32}$ Theoretical studies have explained the ambipolar characteristics of electrons and holes with efficient transport properties.

To date, several electron transport layers (ETLs) have been reported, including metal oxides (mainly transition metal oxides), metal oxide composites, and metal oxide heterostructure nanoparticles.

The crystal structure of hybrid perovskite materials and hybrid PSCs is well known, and the crystal structure analysis has been discussed thoroughly by different groups. ${ }^{1}$ There have been more than 500 articles published within a 5 year span with different device geometry from the concept of dye sensitized solar cells (DSSC) $^{2}$ to $\mathrm{p}-\mathrm{n} / \mathrm{p}-\mathrm{i}-\mathrm{n}$ geometry, ${ }^{33}$ bulk hetero-junction solar cells, ${ }^{34-36}$ and inverted planar structure. ${ }^{37-40}$ Efficiency increased in order from the initial PSC invented by Miyasaka's group. ${ }^{2}$ Later work by different groups improved the efficiency by using different materials from the bottom to the top electrode. This was found to be the easiest way to improve the power conversion efficiency (PCE) by increasing the open circuit voltage $\left(V_{\mathrm{oc}}\right)$ and short circuit current $\left(J_{\mathrm{sc}}\right)$ in the early stages of device research.

The ETL, sometimes called the electron extraction layer or electron collection layer, is where electrons are injected from 
the absorber layer, transported through the electron transporting materials (ETM), and finally collected by the electrode. Sometimes the ETL is replaced by a composite photoelectrode to improve the charge collection efficiency by lowering the series resistance. ${ }^{34-36}$ Moreover, a one-dimensional nanorod ETL provides fast charge transport in a photovoltaic cell. Excellent pore filling achieved by manipulating the gaps between the nanorods and nanosheets was found to be beneficial for enhancing the fill factor (FF) and PCE. ${ }^{41-52}$ The gaps between the nanorods can be controlled by the concentration of the solution and seed nanoparticle films. The efficient charge collection leads to ideal current-voltage behaviour. This is a method by which to improve the external quantum efficiency (EQE), giving maximum efficiency without thermalization.

A schematic diagram of device architecture of the PSC is presented in Fig. 1. The simple PSC consists of an electron transport layer/perovskite/hole transport layer on the FTO/glass substrate. Low and high work function electrodes can be used at the ETL and hole transport layer (HTL) sides, respectively. The balanced diffusion length of electron and hole is more than $500 \mathrm{~nm}$ in a perovskite absorber, which inhibits charge recombination in the perovskite absorber. ${ }^{25,26}$ Recently, Dong et al. reported electron-hole diffusion length of more than 175 microns in $\mathrm{CH}_{3} \mathrm{NH}_{3} \mathrm{PbI}_{3} .{ }^{27}$ Therefore, a smooth electron injection requires after charge separation for further process. Sometimes a compact hole blocking layer is used before the ETL ${ }^{53,54}$ and an electron blocking layer ${ }^{55,56}$ is used before the HTL to block the excess hole and electron at either side, respectively. Some earlier studies focused on compact hole blocking layer (HBL) being beneficial for PCE by blocking the hole from the ETL side. ${ }^{53,54}$ The electron and hole clouding in the device architecture leads to a high recombination rate. Using a planar hetero junction PSC, the PCE can be significantly improved by provision of a proper path for both electron and hole.

In this review, we discuss the material and electrical aspects of the importance of the ETL along with their device physics. There is evidence that the exciton might dissociate at the ETL/

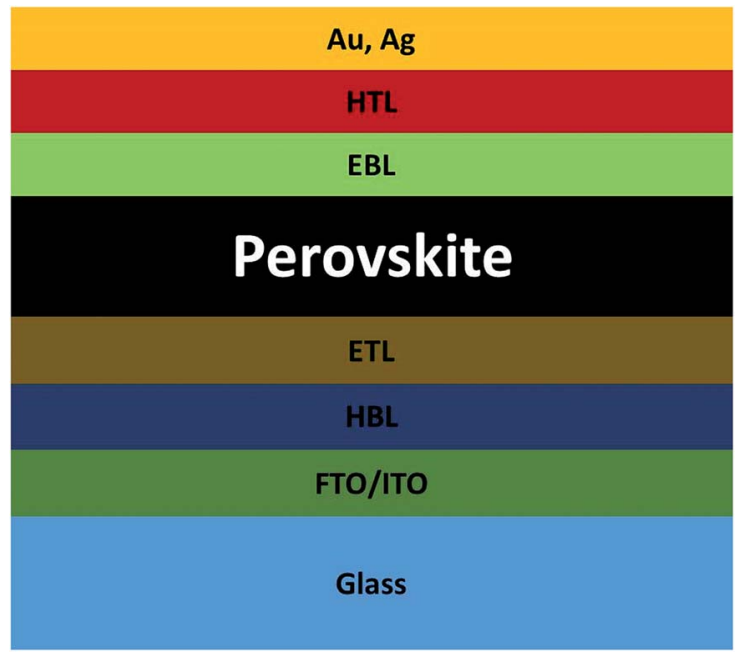

Fig. 1 Schematic of perovskite solar cell. perovskite and perovskite/HTL interfaces. The other factor is exciton diffusion and separation, which is not clearly understood in PSCs. Low exciton energy in perovskite appears to have benefit for high exciton diffusion length, which is an advantage over polymer/organic solar cells. Another important factor is that PSCs fit to inorganic as well as polymer/organic ETL and HTL. Inorganic ETL/HTL has a longer electron/hole diffusion length compared with organic/polymer ETL/HTL. It has been reported that hybrid solar cells do not necessarily need a HTL but do need an ETL/scaffold. ${ }^{57}$ So choice of the proper ETL for PSC is vital. Several reviews have been reported within a short period of time on PSC research. ${ }^{58-66}$

In this review, we summarize different ETL used in hybrid PSC and explore how design of ETL helps to improve the overall device performance. We also discuss how to improve solar cell efficiency in terms of improving charge injection, charge collection, charge separation, and charge transport in ETM. These parameters are interlinking to achieve the overall performance. We also address the effect of microstructure and morphology of ETL materials and how to achieve better pore filling, and composite structure to achieve high electron injection and transport on open circuit voltage. Finally, we review the different processing methods of ETL and their advantages and disadvantages. Herein, the most recent results of this particular optimization process such as annealing temperature and annealing time are reviewed, and how certain ETM retard the charge recombination.

\section{Characteristics of electron transporting layer}

The most important characteristic of an ETL is that it must satisfy band alignment with the perovskite layer, i.e. it should have lowest unoccupied molecular orbital (LUMO) and highest occupied molecular orbital (HOMO) higher than the perovskite active layer. It must have high transmittance in the UV-Vis region so that a photon can pass through easily and be absorbed by the perovskite absorber. Exciton generation via light absorption, across the perovskite layer, must be dissociated before collection either by the ETL or HTL. The exciton dissociation mechanism was explained by Savenije et al. ${ }^{68}$ Excitons can be dissociated at the ETL/perovskite or perovskite/HTL interfaces. Recently, studies showed that the electron and hole diffusion lengths exceed $500 \mathrm{~nm}$ and $1000 \mathrm{~nm}$ for $\mathrm{CH}_{3}$ $\mathrm{NH}_{3} \mathrm{PbI}_{3}$. X-ray diffraction (XRD) and transmission electron microscopy (TEM) analysis of the different groups showed that perovskite films were highly crystalline and defect-free using the one step or two step methods..$^{\mathbf{1 0 , 1 8 - 4 9}}$

\section{Different ETL materials used in perovskite solar cells}

A number of metal oxides, such as $\mathrm{TiO}_{2}, \mathrm{ZnO}, \mathrm{SnO}_{2}, \mathrm{SiO}_{2}, \mathrm{ZrO}_{2}$, can either be used as ETL or scaffold material. Each material has specific advantages to boost the PCE. Two types of solution process have been used to fabricate PSC. One-step deposited 
perovskite led to average PCE of $8.19 \%$ from rutile-perovskite solar cells and $7.23 \%$ from anatase-perovskite solar cells. Nanova et al. predicted that an optimum porosity and an optimum over layer of perovskite is necessary to control the shunt resistance and series resistance. ${ }^{69}$ Using chemical bathdeposited rutile thin films and $\mathrm{TiCl}_{4}$ treatment with different concentrations, Yella et al. successfully modified the particle size of rutile $\mathrm{TiO}_{2}$ to give PCE as high as $13.7 \%{ }^{70}$

A complete list of electron, hole injection and exciton annihilation processes is described by Luo et al. ${ }^{66}$ The large variety of ETL/ETM makes it hard to define the characteristics of the ideal ETL. In terms of considering the band offset between the ETL/ perovskite, Minemoto et al. theoretically calculated that the band offset between the ETL/absorber and HTL/absorber should be $0.0-0.3 \mathrm{eV}$, as shown in Fig. $2 .^{67}$ Fig. 2 shows simulated $J-V$ curves of PSC with different CBO values for the buffer/ absorber interface.

\section{3a. Metal oxide as ETL materials}

The PSC was initiated by Miyasaka's group (Tokyo Univ.) in $2009 .^{2}$ Using two different types of organo-lead halide perovskite nanocrystals, $\mathrm{CH}_{3} \mathrm{NH}_{3} \mathrm{PbBr}_{3}$ and $\mathrm{CH}_{3} \mathrm{NH}_{3} \mathrm{PbI}_{3}$, they efficiently sensitized $\mathrm{TiO}_{2}$ for visible-light conversion in photoelectrochemical cells with photovoltage of $0.97 \mathrm{~V}$ and PCE limited to $3.8 \%$. Later work by Park's group (Sungkyunkwan Univ.), Snaith's group (Oxford Univ.), and Gratzel's group (Ecole Polytechnic) tremendously advanced research in PSC and achieved efficiency of more than 15\%. Initially, the PSC required a glove box to control the atmosphere. Recently, Yang's (UCLA) research group reported $19.3 \%$ efficient PSC using a polyethyleneimine (PEI) thin layer on $\mathrm{TiO}_{2}$ as ETM fabricated in air. ${ }^{71}$ In addition, doped ETM was shown to improve efficiency by tuning the band gap and Fermi level, which can increase/ decrease the open circuit voltage. Using n-type doping in transition metal oxide ETM, the Fermi level can be increased, which

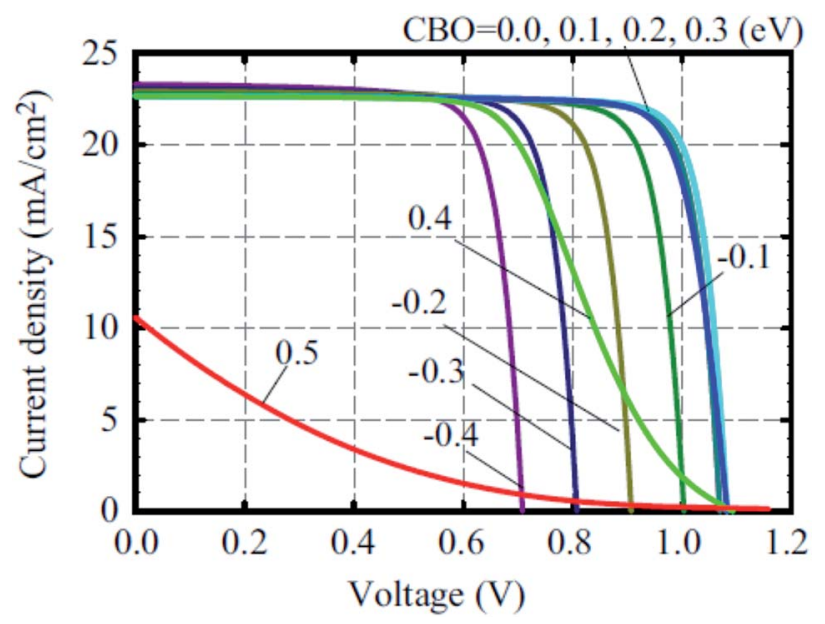

Fig. $2 J-V$ curves of perovskite solar cells with different $\mathrm{CBO}$ values of buffer/absorber interface. Here, the VBO of the absorber/HTM interface was set to 0 and the interface defect density of IDL 1 was set to $10^{16} \mathrm{~cm}^{-3} \cdot 67$ allows the electron to have a smooth injection from the perovskite active layer. Many groups have also used core-shell nanoparticles $\mathrm{Al}_{2} \mathrm{O}_{3} / \mathrm{ZnO},{ }^{72} \mathrm{TiO}_{2} / \mathrm{MgO},{ }^{73}$ and $\mathrm{WO}_{3} / \mathrm{TiO}_{2}$ (ref. 74) for charge retardation, and improved charge recombination resistance by insulating material with efficient charge injection and charge transport.

To date, $\mathrm{TiO}_{2}$ is the ETL material most widely used by different research groups. But, Snaith et al. pointed out that a $\mathrm{TiO}_{2}$-based PSC had lower stability than a $\mathrm{TiO}_{2}$-free PSC. $^{75}$ They studied the stability of ss-DSSC and PSC using transient absorption spectroscopy (Fig. 3). Snaith's group initiated the idea that the absorption tails of mesoporous $\mathrm{TiO}_{2}$ extend into the visible region, which may degrade the stability over a longer timescale. ${ }^{76}$ They suggested that a low cost UV filter could efficiently block the UV and enhance the stability for a longer period of time.

Ultra-thin amorphous $\mathrm{TiO}_{x}$ provides uniformity and homogeneity in short range order, giving more highly stable electronic properties than mesoporous $\mathrm{TiO}_{2}$. A $12.2 \%$ efficient PSC with high bending and durability was achieved using $20 \mathrm{~nm}$ of atomic layer deposited (ALD) $\mathrm{TiO}_{x}$ by Kim et al. ${ }^{18}$

Cadmium selenide (CdSe) has a band gap of $1.8 \mathrm{eV}$, with HOMO $0.5 \mathrm{eV}$ lower than the perovskite active layer and LUMO $0.6 \mathrm{eV}$ higher than the perovskite active layer. CdSe nanocrystal used as an electron transport/extraction layer for PSC shows PCE up to $11.7 \% .^{78}$ Strong PL quenching has been observed in $\mathrm{CdSe} / \mathrm{CH}_{3} \mathrm{NH}_{3} \mathrm{PbI}_{3} /$ Spiro-OMeTAD. The PL quenching effect is necessary in PV devices for better charge separation and recombination resistance. $\mathrm{SnO}_{2}$ shows better environmental stability than $\mathrm{TiO}_{2}$, as reported by Song et al. ${ }^{79}$ Using the concept of light scattering efficiency, Park et al. used $\mathrm{TiO}_{2}$ nanohelix ETL deposited by oblique-angle e-beam evaporation to produce hysteresis-free PSC. ${ }^{80}$ The drawback of using $\mathrm{TiO}_{2}$ in PSCs is that it must be annealed at high temperature, which can be a hindrance in commercialization as well as use in flexible devices as the substrate cannot withstand such high temperatures. While mesoporous $\mathrm{TiO}_{2}$ incorporated PSCs have shown good efficiency, their counterpart, the planar type PSC typically suffers from hysteresis issues. Recently several groups have addressed this issue by replacing the $\mathrm{TiO}_{2}$ with low temperature processed $\mathrm{SnO}_{2}$ in planar structures. $\mathrm{SnO}_{2}$ has advantages over $\mathrm{TiO}_{2}$ in terms of its high electron mobility, anti-reflection property, and deeper conduction band, which could increase charge transfer from perovskite to ETL and reduce charge accumulation at the interface. Weijun Ke et al. deposited $\mathrm{SnO}_{2}$ by spin-coating precursor solutions of $\mathrm{SnCl}_{2} \cdot \mathrm{H}_{2} \mathrm{O}$ and heating in the air at $180{ }^{\circ} \mathrm{C}^{\mathbf{1 4 7}} \mathrm{A}$ high efficiency of $17.21 \%$ was achieved using this method. Although less than in the planar $\mathrm{TiO}_{2}$ structure, hysteresis was still present in PSCs made using this method. Qi Jiang et al. obtained a certified high efficiency of $19.9 \%$ by employing solution-processed $\mathrm{SnO}_{2}$ at a low temperature of $150{ }^{\circ} \mathrm{C}$, which was almost free of hysteresis. ${ }^{148}$ However, passivation of the $\mathrm{PbI}_{2}$ phase in the perovskite layer was introduced in this study, which might have played a role in such a high efficiency of the device. Researchers have also employed atomic layer deposited (ALD) $\mathrm{SnO}_{2}$ in a PSC, which served as the top cell in a tandem device. An efficiency of $20 \%$ was obtained 

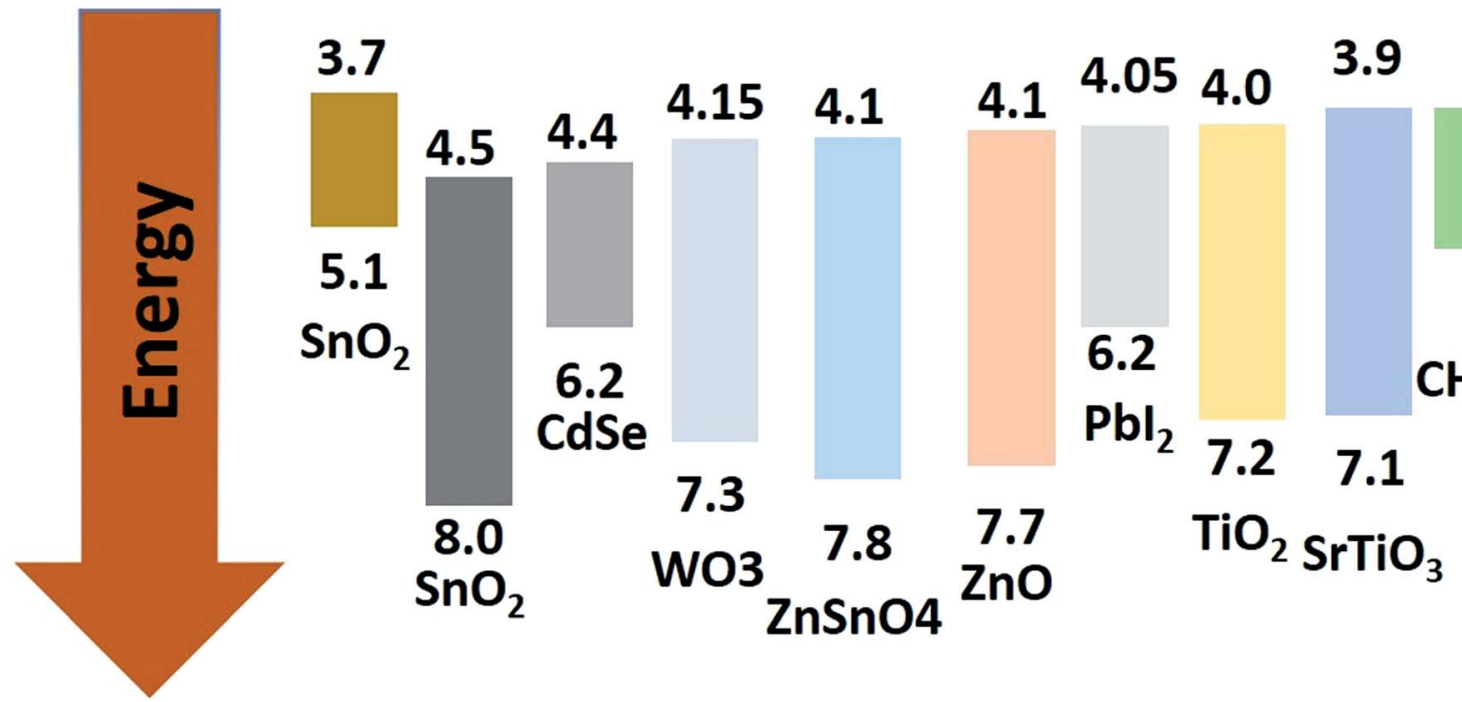

Fig. 3 Band energy diagram of different ETL with respect to perovskite.

with this configuration. However, as ADL is not cost-effective commercially, the researchers employed a combination of spin-coating and chemical bath deposition of $\mathrm{SnO}_{2}$ to form the ETL. ${ }^{149}$ Devices made using this method showed better performance than devices made by ALD, mainly because of an improved FF. The higher roughness of the $\mathrm{SnO}_{2}$ achieved from the new technique results in better contact of the ETL and perovskite layer, thus increasing the FF. The devices showed a mild hysteresis, although much better than that of the planar $\mathrm{TiO}_{2}$ devices, and showed a highest efficiency of $21 \%$ (planar structure). The devices retained $82 \%$ of efficiency after ageing for $60 \mathrm{~h}$ under illumination of $100 \mathrm{~mW} \mathrm{~cm} \mathrm{c}^{-2}$. This is similar to the ageing behaviour of high temperature mesoporous films. A steady-state efficiency of $17.54 \%$ was also obtained using an effective interface engineering technique for planar PSCs employing $\mathrm{SnO}_{2}$ as an electron selective layer. ${ }^{150}$

\section{3b. Scaffold material for perovskite solar cells}

Unusually high efficiency was reported using $\mathrm{SiO}_{2}, \mathrm{Al}_{2} \mathrm{O}_{3}$, and $\mathrm{ZrO}_{2}$ as scaffold material in PSC. A PCE of up to $\sim 10 \%$ was reported by different research groups using $\mathrm{SiO}_{2},{ }^{81} \mathrm{Al}_{2} \mathrm{O}_{3},{ }^{82,83}$ and $\mathrm{ZrO}_{2}$ (ref. 84) as scaffold material. A material with lower conduction band edge, and higher valence band edge can effectively inject electron and block hole from the perovskite layer, which can improve the recombination resistance for a highly efficient PSC. For $\mathrm{SiO}_{2}, \mathrm{Al}_{2} \mathrm{O}_{3}$, and $\mathrm{ZrO}_{2}$, the band gap is larger, and the conduction band edge is much higher than the conduction band of the perovskite layer which prevents smooth electron injection into both $\mathrm{SiO}_{2}$ and $\mathrm{ZrO}_{2}$. Thus, the excited electron remains in the conduction band of the perovskite layer for a longer time. It was also proposed that the perovskite layer exhibits an ambipolar nature and that the electron can remain in the conduction band with only hole transported to the HTL. Bi et al. reported $\mathrm{ZrO}_{2}$ as a scaffold material and compared the PCE with $\mathrm{TiO}_{2}$ ETL. $^{84}$ Their results showed that $\mathrm{ZrO}_{2}$ (PCE:
10.8\%) had higher efficiency than $\mathrm{TiO}_{2}$ (PCE: 9.8\%). Although the band alignment is not fulfilled when $\mathrm{ZrO}_{2}$ is used as scaffold material, the higher photovoltage and higher electron lifetime make $\mathrm{ZrO}_{2}$ an efficient scaffold material, as shown in Fig. 4. $\mathrm{Al}_{2} \mathrm{O}_{3}$ acts as an excellent protective material for degradation of PSC. As can be seen in Fig. 5, a comparative study by Niu et al. ${ }^{82}$ showed that $\mathrm{Al}_{2} \mathrm{O}_{3}$ retained the optical absorbance of perovskite and maintained the stability of the PSC by extracting moisture from the perovskite layer (Fig. 7).

Using an ultra-thin $\mathrm{Al}_{2} \mathrm{O}_{3}$ layer, excellent moisture and humidity stability was demonstrated by Dong et al. ${ }^{83}$ Using computational analysis along with experimental results, they proved that thin layer $\mathrm{Al}_{2} \mathrm{O}_{3}$ acts an excellent absorber of $\mathrm{H}_{2} \mathrm{O}$ from the perovskite layer.

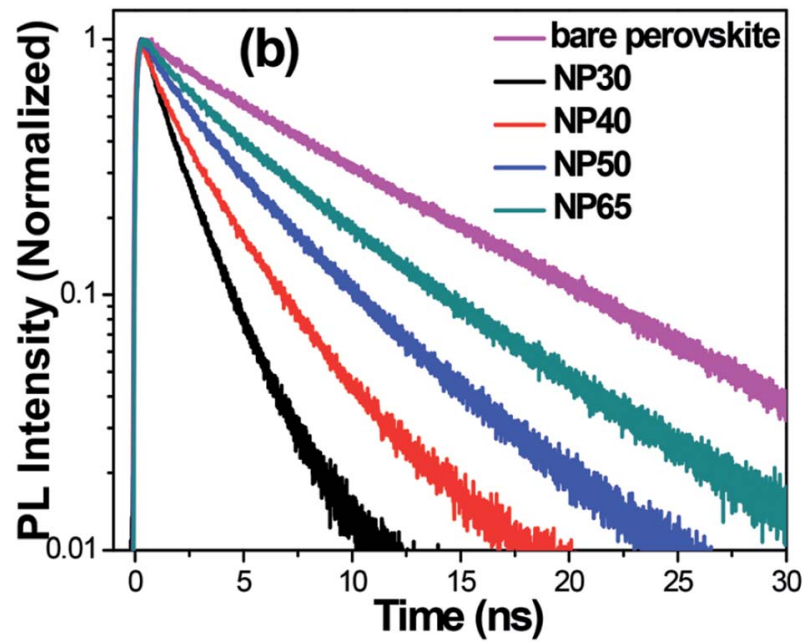

Fig. 4 TR-PL decays of bare $\mathrm{CH}_{3} \mathrm{NH}_{3} \mathrm{Pbl}_{3}$ deposited on Pyrex glass and the $\mathrm{FTO} / \mathrm{TiO}_{2} / \mathrm{CH}_{3} \mathrm{NH}_{3} \mathrm{Pbl}_{3}$ devices employing NP30, NP40, NP50, and NP65. It can be seen clearly that the TR-PL decay is accelerated with decrease in the size of $\mathrm{TiO}_{2} \mathrm{NPs}$. The time resolution of the TR-PL measurement was $\sim 190$ ps. $^{77}$ 


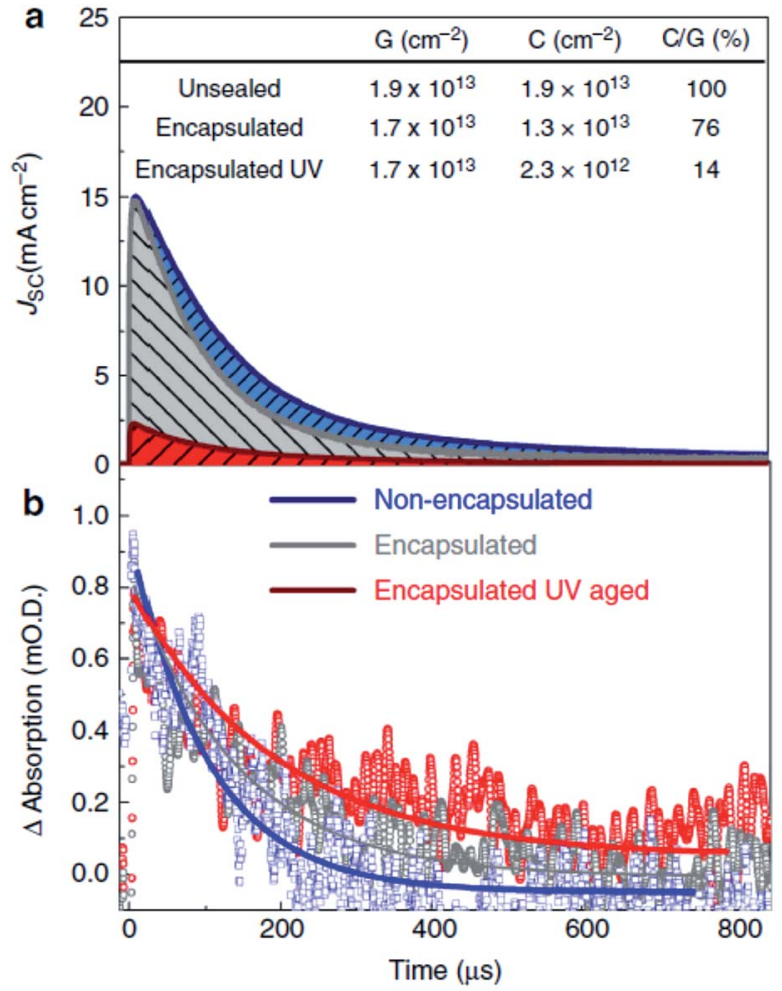

Fig. 5 Current extraction and transient absorption spectroscopy of $\mathrm{TiO}_{2}$-based solar cells. In the top panel (a), the current collected from full perovskite-sensitized $\mathrm{TiO}_{2}$ solar cells with semi-transparent electrodes (15 nm gold) after a $10 \mathrm{~ns}$ laser pulse $(550 \mathrm{~nm})$ is plotted against time after the excitation. Non-encapsulated (blue), encapsulated after ambient light exposure (grey), and encapsulated after UV aging (red) $\left(5 \mathrm{~min}\right.$ at $40 \mathrm{~mW} \mathrm{~cm}^{-2}, 365 \mathrm{~nm}$ ) are compared. The area underneath the curves represents the total amount of collected charge. In the bottom panel (b), the transient absorption trace at short circuit of the hole on Spiro-OMeTAD is probed at $510 \mathrm{~nm}$, performed simultaneously with the current extraction. The lines are merely guides to the eye. The table in the figure shows the charge generated (G, estimated from the early time transient absorption signal), collected $(C$, by integrating the current decay), and the ratio between the two as a percentage $(\mathrm{C} / \mathrm{G})$. The laser intensity was $80 \mathrm{~mJ} \mathrm{~cm}^{-2}$, giving charge densities similar to those found in devices under operating conditions. ${ }^{75}$

\section{3c. Organic ETL materials}

Metal oxide-free PSC have been prepared using organic semiconductors. Many groups have reported organic ETL such as PEHT, PCBM, PEHT:PCBM ${ }^{85-95}$ composites to achieve high
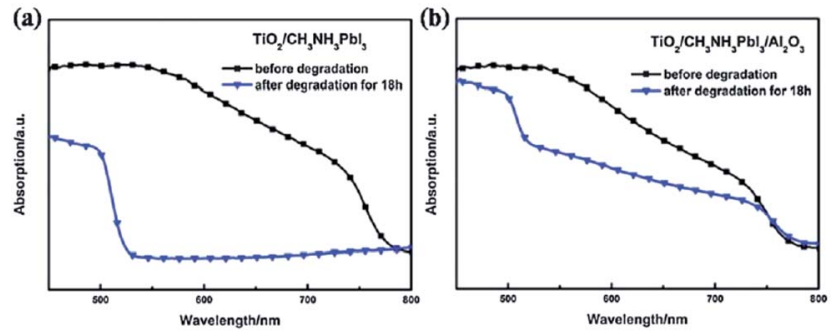

Fig. 6 UV-Vis spectra of sensitized films. (a) Film of $\mathrm{TiO}_{2} / \mathrm{CH}_{3} \mathrm{NH}_{3} \mathrm{Pbl}_{3}$ before and after degradation, (b) Film of $\mathrm{TiO}_{2} / \mathrm{CH}_{3} \mathrm{NH}_{3} \mathrm{Pbl}_{3} / \mathrm{Al}_{2} \mathrm{O}_{3}$ before and after degradation. The degradation time is $18 \mathrm{~h}^{83}$
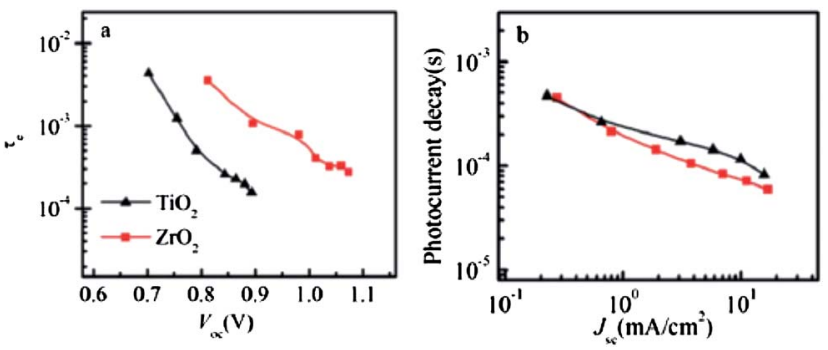

Fig. 7 (a) Electron lifetime as a function of open circuit voltage in Spiro-OMeTAD/ $\mathrm{CH}_{3} \mathrm{NH}_{3} \mathrm{Pbl}_{3} / \mathrm{ZrO}_{2}$ (or $\mathrm{TiO}_{2}$ ) solar cells. (b) ${ }^{84}$ Photocurrent transient decay occurs as a function of short-circuit current in Spiro-OMeTAD/CH $3 \mathrm{NH}_{3} \mathrm{Pbl}_{3} / \mathrm{ZrO}_{2}$ (or $\mathrm{TiO}_{2}$ ) solar cells. ${ }^{84}$

efficiency in inverted PSC. Using an organic or polymer material with metal oxide scaffold/electron blocking layer, PSC can be prepared with improved efficiency. Many polymers satisfy the condition mentioned in the above section that the LUMO must be lower than that of the perovskite layer. $\mathrm{A} \mathrm{NiO}_{2}$ electron blocking layer and HTL with PCBM/BCP as an ETL was reported by Wang et al. ${ }^{85}$ With planar hetero-junction device architecture as ITO/ PEDOT:PSS/perovskite/ $\mathrm{PC}_{61} \mathrm{BM} / \mathrm{Ca} / \mathrm{Al}$, Chiang et al. reported $16.21 \%$ efficiency with a remarkably high $V_{\mathrm{oc}}$ of $1.05 \mathrm{~V}$ and FF of 0.78. ${ }^{86} \mathrm{ITO} / \mathrm{PEDOT}: \mathrm{PSS} /$ polyTPD/CH $\mathrm{CH}_{3} \mathrm{NH}_{3} \mathrm{PbI}_{3} / \mathrm{Au}$ with an ETL and HTL was realized by Malinkiewicz et al. They compared the device performance with ETL and HTL using ITO/PEDOT:PSS/polyTPD/ $\mathrm{CH}_{3} \mathrm{NH}_{3} \mathrm{PbI}_{3} / \mathrm{HBL} / \mathrm{Au}^{87}$ Using ITO/PEDOT:PSS $/ \mathrm{CH}_{3} \mathrm{NH}_{3} \mathrm{PbI}_{3-x^{-}}$ $\mathrm{Cl}_{x} / \mathrm{PCBM} / \mathrm{Al}$ as the device structure on glass as well flexible substrate, You et al. reported PCE of $11.5 \%$ and $9.2 \%$ on rigid and flexible substrates, respectively. ${ }^{88}$

The ETL provides a scaffold material for the perovskite layer to crystallize well to form pinhole-free compact films. As is known, the crystallization and nucleation behaviour of the perovskite layer depends on the nucleation site of the substrate, so careful treatment of ETM is crucial to obtain a uniform, compact, and smooth perovskite layer with lesser voids to avoid unnecessary leakage of current. In addition to use of different ETM discussed above, Ke et al. claimed that PSC do not necessarily need ETM. Ultravioletozone treatment of ITO substrates, with a planar junction architecture processed by a solution method, has achieved a PCE of over $14 \%$ and an open-circuit voltage of $1.06 \mathrm{~V}$ (Fig. 8). ${ }^{96}$

With an ETL, a high conversion efficiency of $\sim 8.39 \%$ along with a high short circuit current $\left(J_{\mathrm{sc}}\right)$ of $\sim 15.24 \mathrm{~mA} \mathrm{~cm}{ }^{-2}$, an open circuit voltage $\left(V_{\mathrm{oc}}\right)$ of $\sim 0.830 \mathrm{~V}$, and a high fill factor $(\mathrm{FF})$ of $\sim 0.66$ was obtained using Ti-coated ITO/PET substrate. Intensity-modulated photocurrent (IMPS)/photovoltage spectroscopy (IMVS) studies demonstrated that the fabricated flexible PSC had considerably reduced recombination rate and higher charge transfer rate. ${ }^{97}$

\section{3d. Charge retardation and charge separation using core- shell nanoparticles}

$\mathrm{TiO}_{2}$ is the most commonly used ETL in PSC. Chandiran et al. reported $11.5 \%$ efficiency by controlling a thin layer of atomic layer deposition (ALD) deposited mesoporous $\mathrm{TiO}_{2} \cdot{ }^{98}$ Using mesoporous $\mathrm{TiO}_{2}$ deposited by a spin-coating method and 


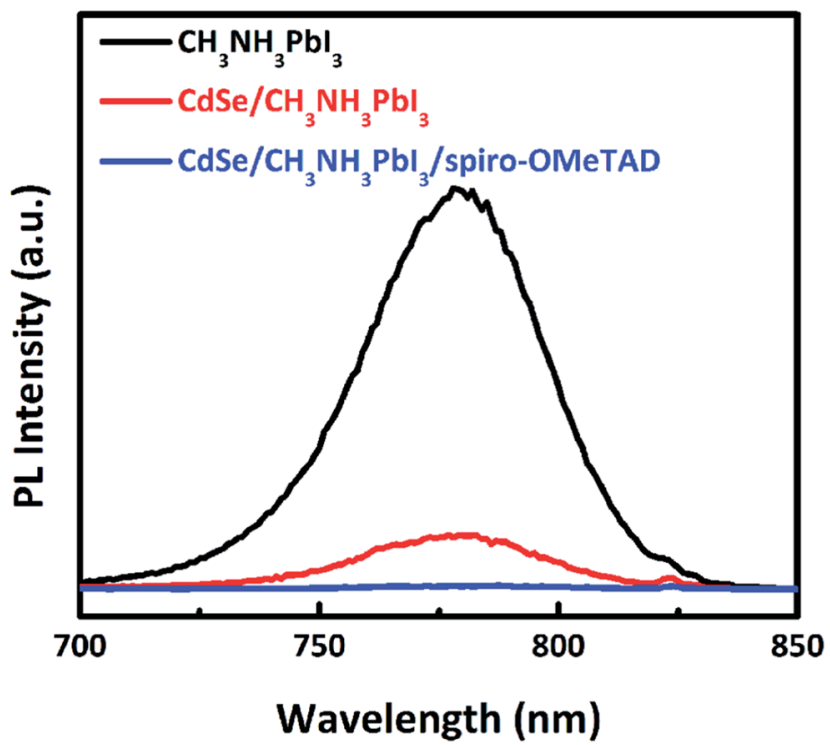

Fig. 8 The $\mathrm{PL}$ spectra of $\mathrm{CH}_{3} \mathrm{NH}_{3} \mathrm{Pbl}_{3}, \mathrm{CdSe} / \mathrm{CH}_{3} \mathrm{NH}_{3} \mathrm{Pbl}_{3}, \mathrm{CdSe} /$ $\mathrm{CH}_{3} \mathrm{NH}_{3} \mathrm{Pbl}{ }_{3} / \mathrm{Spiro}-\mathrm{OMeTAD}$ on glass substrates. The excited wavelength is $600 \mathrm{~nm}^{78}$

further changing to core-shell NPs after ALD deposited $\mathrm{TiO}_{2}$, improved the efficiency by retarding charge recombination. The purpose of a thin layer of high band gap materials is to eliminate the contact between the electrode and HTL because the perovskite active layer shows pinholes on thermal treatment during device fabrication, and also to passivate the surface defects on nanoparticulate $\mathrm{TiO}_{2}\left(\mathrm{np}-\mathrm{TiO}_{2}\right)$ mesoporous films. The schematic in Fig. 9 shows that cross-linking core-shell NPs are extended up to the bottom of the electrode.

Without an ETL, electrons suffer a sudden voltage drop which may degrade the device performance. A novel ITO/TiO core-shell nanostructured photoanode was fabricated by Han et al. ${ }^{99}$ using VLS grown ITO nanowire with ALD deposited $\mathrm{TiO}_{2}$, which gave better electron injection and charge collection efficiency compared with $\mathrm{TiO}_{2}$ ETL. At the same time, this kind of nanostructure gives lower series resistance to the devices, with

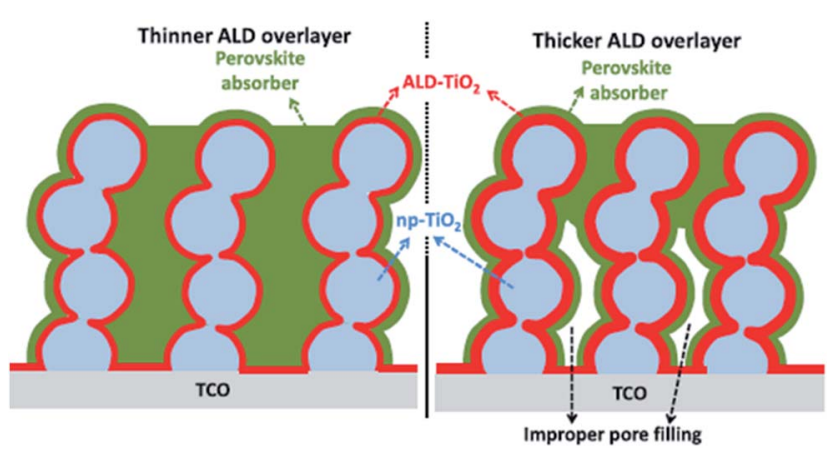

Fig. 9 Block diagrams of mesoscopic photoanodes with thinner (left) and thicker (right) ALD $\mathrm{TiO}_{2}$ overlayer (red) deposited on the mesoporous nanoparticle $\mathrm{TiO}_{2}$ (light blue) films. The np- $\mathrm{TiO}_{2}-\mathrm{ALD} \mathrm{TiO}$ film is infiltrated with $\mathrm{CH}_{3} \mathrm{NH}_{3} \mathrm{Pbl}_{3}$ absorber (green). For thicker ALD $\mathrm{TiO}_{2}$ overlayers, the pore diameter is reduced and improper pore filling of the perovskite absorber is highlighted (right). ${ }^{98}$ a lesser diffusion path for charge carrier, and acts as both photoanode and ETL for DSSC as well as hybrid PSC. The same concept was implemented using $\mathrm{Al}_{2} \mathrm{O}_{3} / \mathrm{ZnO}$ nanoparticle to improve the efficiency in PSC. ${ }^{35}$ Such nanoarchitectures could be implemented for ITO/ZnO, ITO/ $/ \mathrm{Al}_{2} \mathrm{O}_{3}$ and ITO $/ \mathrm{V}_{2} \mathrm{O}_{5}$, etc., because these metal oxides have already been tested as efficient ETL materials and can be deposited by the ALD process.

$\mathrm{WO}_{3}$ is not considered to be an efficient ETM for DSSC. ${ }^{\mathbf{1 0 0 , 1 0 1}}$ In comparison with conventional $\mathrm{TiO}_{2} \mathrm{ETL}, \mathrm{WO}_{x}$ exhibited comparable light transmittance but had higher electrical conductivity. PSCs using $\mathrm{WO}_{3}$ ETL exhibited comparable photoelectric conversion efficiency with $\mathrm{TiO}_{2}$-based PSCs, larger short-circuit current density, and high lower open-circuit voltage. ${ }^{102}$ However, if a thin layer of $\mathrm{TiO}_{2}$ is coated on the $\mathrm{WO}_{3}$, better electron injection can be observed in comparison with the $\mathrm{WO}_{3}$ alone. This leads to high charge collection efficiency and retards the recombination in PSC. Mahmood et al. reported a mesoscopic $\mathrm{WO}_{3} / \mathrm{TiO}_{2}$ nanostructure to get a smooth electron injection to get high $V_{\mathrm{oc}}$ and PCE. ${ }^{47}$ As the FF depends on the series resistance, shunt resistance, and diode characteristics, careful choice of nanostructure, thickness, and pore filling could provide improved FF. A recorded $V_{\text {oc }}$ (approx $\sim 1.3 \mathrm{~V}$ ) was achieved by tailoring both a low-lying HOMO level as well as the appropriate electronic and optical properties by Edri et al. ${ }^{57}$ using a $\mathrm{TiO}_{2} /$ alumina/ $\mathrm{CH}_{3} \mathrm{NH}_{3} \mathrm{PbBr}_{3} / \mathrm{PDI}$ structure. Their efficiency was limited, however, to $0.56 \%$.

a)

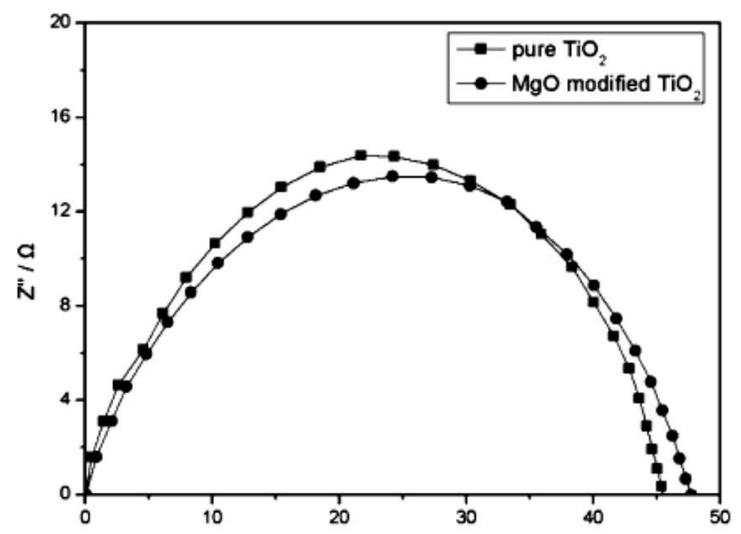

b)

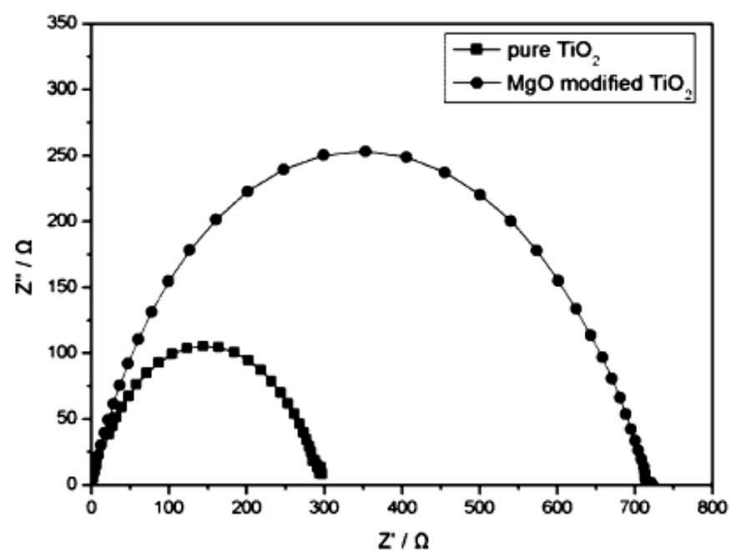

Fig. 10 EIS of PSC with and without MgO coating under (a) light illumination and (b) dark conditions. ${ }^{104}$ 
A high band gap material on $\mathrm{m}-\mathrm{TiO}_{2}$ ETL would have reduced the charge recombination rate. PSCs are sensitive to moisture and humidity. It is believed that $\mathrm{H}_{2} \mathrm{O}$ can decompose $\mathrm{CH}_{3} \mathrm{NH}_{3} \mathrm{PbI}_{3}$ into $\mathrm{PbI}_{2}$ and $\mathrm{CH}_{3} \mathrm{NH}_{3} \mathrm{I}$, which can degrade performance of PSC. ${ }^{\mathbf{8 2}, 103}$ The surface of $\mathrm{m}-\mathrm{TiO}_{2}$ is prone to $\mathrm{H}_{2} \mathrm{O}$ /hydroxyl groups, which interact with the $\mathrm{NH}_{4}$ and $\mathrm{CH}_{3}$ in the perovskite layer, and degrade the charge transport. ${ }^{104}$ Long exposure of $\mathrm{m}-\mathrm{TiO}_{2}$ to air and pre heating or UV treatment before fabrication of the perovskite layer can result in the above interface problem. Hence, some previous reports advised $\mathrm{TiCl}_{4}$ treatment, which can prevent such effects in PSC. ${ }^{53}$ Using a thin layer of $\mathrm{MgO}$ on $\mathrm{m}-\mathrm{TiO}_{2}$, the recombination resistance can be reduced (Fig. 10). ${ }^{53}$

Charge retarding behaviour using heterostructure coreshell nanoparticles is well known in DSCC. Using $\mathrm{MgO} / \mathrm{TiO}_{2}$, $\mathrm{Al}_{2} \mathrm{O}_{3} / \mathrm{TiO}_{2}, \mathrm{ZnO} / \mathrm{TiO}_{2}$ etc., electron-hole recombination can be suppressed. ${ }^{72,73} \mathrm{MgO}$-coated $\mathrm{TiO}_{2}$ nanoparticle (NP)-based electron collecting layers were fabricated by Han et al., to prevent charge recombination at the perovskite/ $/ \mathrm{TiO}_{2}$ interface in PSC. ${ }^{73}$ Open circuit voltage $\left(V_{\mathrm{oc}}\right)$ and fill factor $(\mathrm{FF})$ with $\mathrm{MgO} / \mathrm{TiO}_{2}$ ETL are $4.7 \%$ and $6.1 \%$ higher, respectively, than with mesoporous $\mathrm{TiO}_{2}$ ETL, and the recombination times for $\mathrm{MgO} / \mathrm{TiO}_{2}$ NP-based PSC are about three times longer than that of $\mathrm{TiO}_{2}$ NP-based solar cells. Longer recombination time was achieved by adding an $\mathrm{MgO}$ thin layer which retards the electron-hole recombination. ${ }^{71}$ The detailed mechanism is shown in Fig. 11.

\section{3e. Doping effect}

It is well known that a photoelectrode can efficiently absorb a photon and provide better band alignment to the charge, which can inject to the electrode. Using $\mathrm{Y}^{-\mathrm{TiO}_{2}}(0.5 \% \mathrm{Y})$ can increase the conduction band edge near to the conduction band of perovskite. ${ }^{105}$ Mahmood et al. also reported $\mathrm{Al}$ doped $\mathrm{ZnO}$ as an efficient ETL using an electrospraying method which effectively enhances the charge collection efficiency. ${ }^{106}$

$\mathrm{N}$-type doping leads to an increase in the conduction band edge which can efficiently decrease the charge recombination process. Several n-type dopings have been reported in $\mathrm{TiO}_{2}$ as well as $\mathrm{ZnO}$. Pure anatase mesoporous $\mathrm{TiO}_{2}$ was used as ETL material in the initial stages of PSC research. The band gap of $\mathrm{TiO}_{2}$ is about $3.2 \mathrm{eV}$ with HOMO and LUMO situated at $3.2 \mathrm{eV}$ and $5.4 \mathrm{eV}$, respectively, which is best fit to the energy level diagram. However, doping to the $\mathrm{TiO}_{2}$ improves the conduction band edge as well as the band gap $\mathrm{TiO}_{2}$. For this reason, n-type doping in ETL gives a smooth electron injection from the perovskite layer to ETL (Fig. 12).

In this way, the $V_{\mathrm{oc}}$ can be improved to shorten level, which would raise the FF, and consequently the PCE. n-type doping in $\mathrm{TiO}_{2}$ can be achieved using a number of elements. Using $\mathrm{Sn}$ doped $\mathrm{TiO}_{2}$, Zhang et al. ${ }^{51}$ tuned the band gap of $\mathrm{TiO}_{2}$ and improved the efficiency up to $67 \%$. By n-type doping, the conduction band edge can be increased, which can suppress recombination of electron and hole and provide a smooth electron injection. Using this concept, many n-type doped $\mathrm{TiO}_{2}$

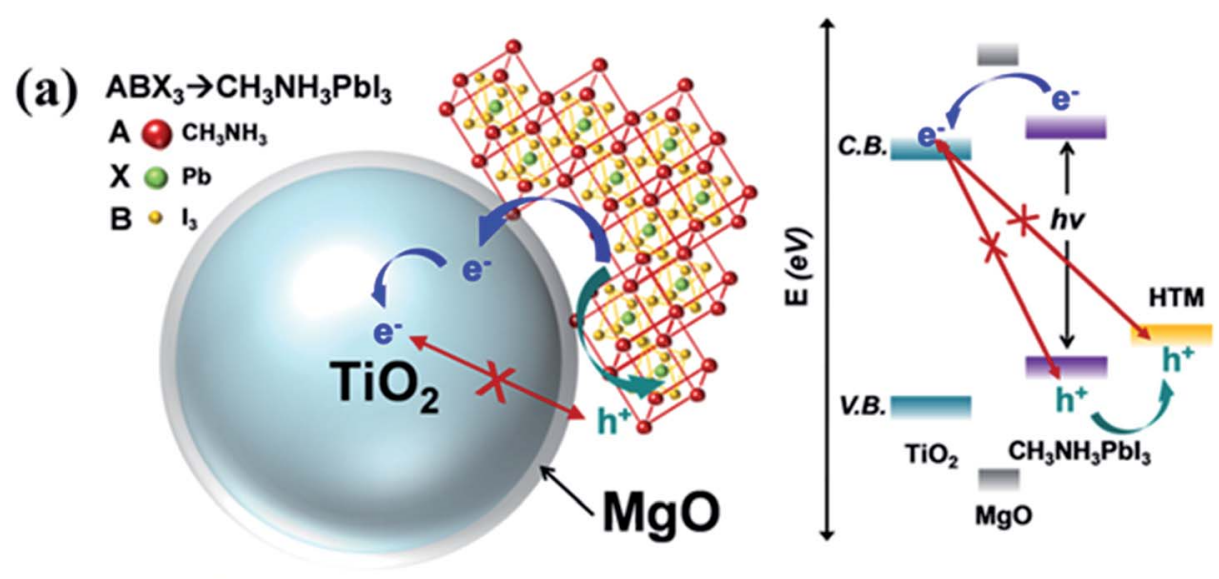

(b)

(c)
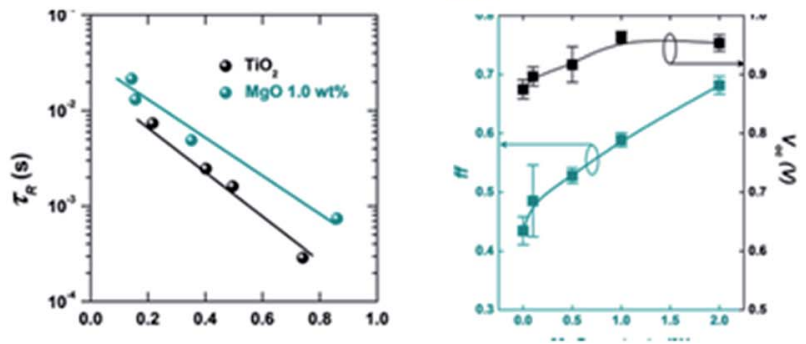

Fig. 11 (a) Schematic representation of the charge transfer mechanism in $\mathrm{TiO}_{2}$-based perovskite solar cell with a $\mathrm{MgO}$ layer, band energy diagram of the $\mathrm{MgO} / \mathrm{TiO}_{2}$ core-shell NP-based perovskite solar cell, (b) electron lifetime of $\mathrm{MgO} / \mathrm{TiO}_{2}$ core-shell NP-based perovskite solar cells compared with $\mathrm{TiO}_{2} \mathrm{NP}$-based perovskite solar cells and (c) open circuit voltage ( $\mathrm{V}_{\mathrm{oc}}$ ) and fill factor (FF) of the $\mathrm{MgO} / \mathrm{TiO} \mathrm{O}_{2} \mathrm{core}-$ shell NPbased perovskite solar cell with varying magnesium methoxide concentrations $(0.1 \mathrm{wt} \%, 0.5 \mathrm{wt} \%$, and $2.0 \mathrm{wt} \%){ }^{73}$ 


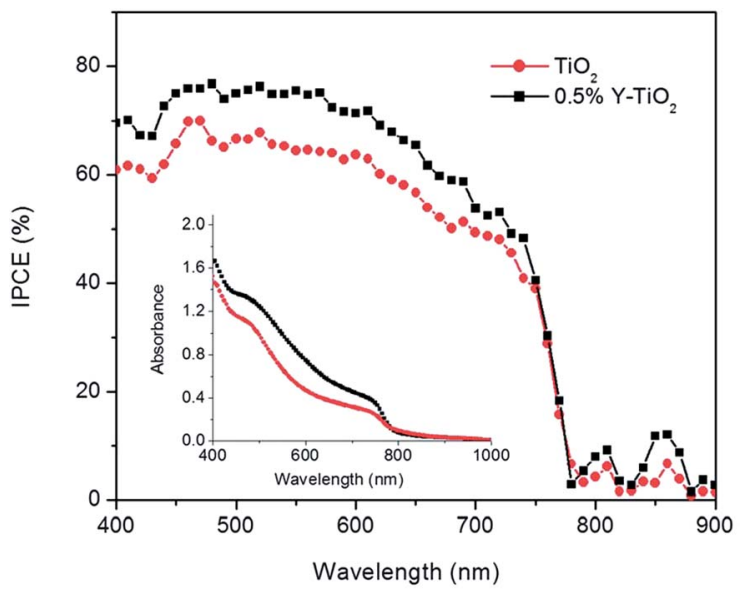

Fig. 12 Incident photon-to-electron conversion efficiency spectra of devices based on $0.5 \% \mathrm{Y}-\mathrm{TiO}_{2}$ (black) and $\mathrm{TiO}_{2}$ (red). The inset shows the UV-Vis absorbance spectra of $0.5 \% \mathrm{Y}-\mathrm{TiO}_{2} / \mathrm{CH}_{3} \mathrm{NH}_{3} \mathrm{Pbl}_{3}$ and $\mathrm{TiO}_{2} /$ $\mathrm{CH}_{3} \mathrm{NH}_{3} \mathrm{Pbl}_{3}$ electrodes. ${ }^{34}$

have been used to get higher $V_{\mathrm{oc}}$. Manseki et al. used $\mathrm{Mg}$ doped $\mathrm{TiO}_{2}$ as ETL to increase the band gap of $\mathrm{TiO}_{2}$ and $\mathrm{CB}$ edge, leading to improved $V_{\mathrm{oc}}{ }^{52}$ Their results showed that the band gap increased up to $1 \mathrm{eV}$ which affects the $V_{\mathrm{oc}}$, increasing it from $587 \mathrm{meV}$ to $802 \mathrm{meV}$. Electron-rich, nitrogen doped $\mathrm{ZnO}$ (N:ZnO) NR-based electron transporting materials (ETMs) with enhanced electron mobility produced using ammonium acetate show consistently higher efficiencies by one to three power points than undoped $\mathrm{ZnO}$ NRs. ${ }^{107}$ Using $\mathrm{Pb}$ doped $\mathrm{TiO}_{2}$ nanofibre, Xiao et al. reported $9.03 \%$ efficient PSC with an HTL. ${ }^{108}$ Using Al-doped $\mathrm{ZnO}$ (AZO) modified $\mathrm{ZnO}$ nanorods as ETL, enhanced $V_{\text {oc }}$ and PCE were achieved (Fig. 13). ${ }^{109}$

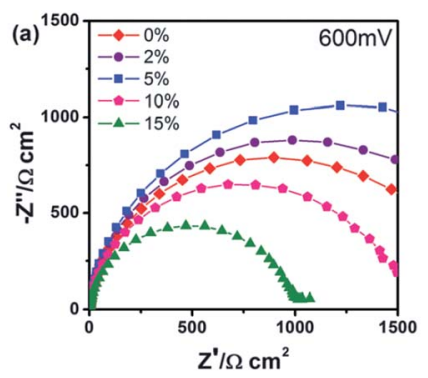

(b)
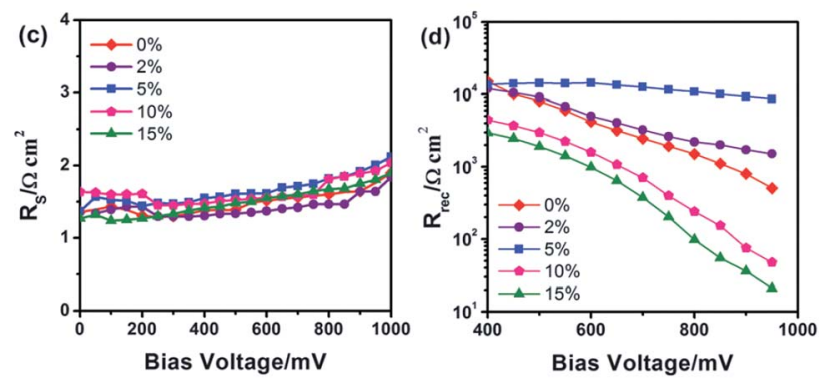

Fig. 13 (a) Nyquist plots of the device treated with $\mathrm{AZO}$ at different $\mathrm{Al}$ doping levels at applied bias $(600 \mathrm{mV})$ under dark conditions. (b) Equivalent circuit employed to fit the IS data. Plots of (c) the series resistance $\left(R_{\mathrm{S}}\right)$ and $(\mathrm{d})$ the charge transport resistance $\left(R_{\text {rec }}\right)$ obtained from IS results as a function of the applied bias. ${ }^{109}$
For flexible PSCs, ALD deposited $\mathrm{TiO}_{2}, \mathrm{ZnO}, \mathrm{SiO}_{2}, \mathrm{HfO}_{2}$ and $\mathrm{ZrO}_{2}$ are better options for growth on flexible substrate. However, other methods such as hydrothermal, spin coating, electrospray method spray deposition are good for PSC fabricated on rigid substrates. Using a hydrothermal method, the microstructure can be easily tuned to tune the optical properties and device architecture. The electrospray method is a better choice for growth of many novel nanostructures with multilayer structure for sensitized and solid state PSC. ${ }^{110}$ Electrospray has many process parameters, and can adjust the thickness as well as morphologies. Magnetron sputtering grown compact $\mathrm{ZnO}$ as ETL was deposited by Liang et al. ${ }^{48}$ They observed $13.4 \%$ and $8.03 \%$ PCE on ITO/glass and ITO/PET substrate. The sheet resistance of $\mathrm{ZnO} / \mathrm{ITO} / \mathrm{glass}$ was limited to $8.0 \mathrm{ohm}$ per $\mathrm{cm}^{2}$, which gave a low series resistance to the device. At the same time, compact ZnO films by magnetron sputtering mean that the shunt resistance would be high enough to give such high efficiency. A complete list of fabrication methods and their electronic properties is given in Table 1. The HOMO, LUMO, and band gap are also listed and the band energy diagram with respect to perovskite is tabulated. As per theoretical study by Minemoto et al. ${ }^{67}$ the band offset between the ETL and perovskite layer should be in the range of $0.0-0.3 \mathrm{eV}$, to give an optimum $V_{\mathrm{oc}}$, which regulates the FF in PSC. This information is useful for fabricating highly efficient PSC by choosing an optimum thickness, microstructure, doping, and device architecture. Band gap tailing by $\mathrm{Nb}$ doping in $\mathrm{TiO}_{2}$ and faster electron injection and electron lifetime was reported by Kim et al. ${ }^{111}$ They showed light $\mathrm{Nd}$ doped $\mathrm{TiO}_{2}$ to have the highest efficiency of $13.4 \%$ (Fig. 14).

Table $1 \mathrm{~J}-V$ curve parameters of several perovskite solar cells employing $\mathrm{TiO}_{2} \mathrm{NPs}$ of various sizes ${ }^{77}$

\begin{tabular}{lclll}
$\begin{array}{l}\text { Solar cell } \\
\text { type }\end{array}$ & $V_{\text {oc }}(\mathrm{mV})$ & $J_{\text {sc }}\left(\mathrm{mA} \mathrm{cm}^{-2}\right)$ & FF (\%) & PCE (\%) \\
\hline PSC-30 & 995 & 21.61 & 66.59 & 14.32 \\
PSC-40 & 1029 & 21.45 & 69.74 & 15.24 \\
PSC-50 & 1049 & 21.58 & 75.94 & 17.19 \\
PSC-65 & 1005 & 21.27 & 72.35 & 15.47
\end{tabular}
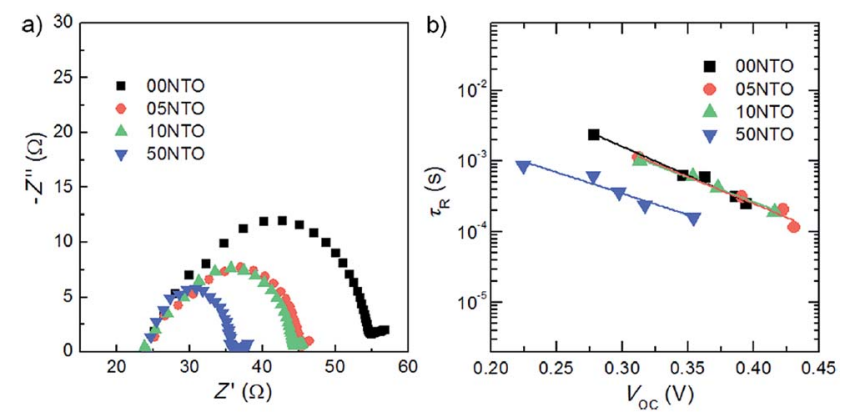

Fig. 14 (a) Nyquist plot of the PSCs measured at open-circuit conditions. The impedance spectra measured in the frequency range of 10 $\mathrm{mHz}$ to $2 \mathrm{MHz}$ at open circuit potential under 1 sun illumination. (b) $t_{\mathrm{R}}$ of the PSCs as a function of $V_{\text {oc }}$. The detailed measurement conditions of $t_{\mathrm{R}}$ are the same as those of the $t_{\mathrm{C}}$ measurements (Fig. 6). ${ }^{111}$ 


\section{3f. Induced dipole effect: the role of polymer on ETL}

Introducing a dipole layer at the $\mathrm{TiO}_{2} /$ perovskite interface can efficiently separate the electron and hole by controlling the polymer thickness, which can reduce the charge recombination in a solar cell. ${ }^{104}$ The existence of oriented permanent dipoles at the $\mathrm{TiO}_{2} /$ perovskite interface is consistent with the hypothesis of an ordered perovskite layer, close to the oxide surface without using polymer. ${ }^{112}$ Photoinduced absorption (PIA) and electron absorption (EA) study confirmed that either non-oriented permanent dipoles and/or likely expectable bulk polarization effects, contribute to the Stark signal. Sometimes a thin polymer layer induced a dipole moment between ETL and the perovskite layer. Polyethylene amine (PEI) which is used as a surfactant to grow $\mathrm{ZnO}$ nanostructure is conserved for induced dipole moment. ${ }^{107}$ Using PEI nanolayer, smooth electron injection was observed by inducing a dipole layer at the $\mathrm{PEI} / \mathrm{TiO}_{2}$ (ref. 71) or $\mathrm{PEI} / \mathrm{ZnO}^{107}$ interface, which can increase the conduction band edge to give smooth electron injection. Moreover, a dipole layer can efficiently separate the electron from the perovskite absorber. Zhou et al. used the same concept to achieve high efficiency, with $\mathrm{Y}^{-} \mathrm{TiO}_{2}$ to improve the efficiency. ${ }^{71}$ Polymers induced the dipole effect and their effects on device performance in different device structures are summarized in Table 2 (Fig. 15).

Table 2 Induced dipole-related polymers and their effect on device performance in PSC

\begin{tabular}{|c|c|c|c|c|c|}
\hline Polymer & Device structure & $J_{\mathrm{sc}}\left(\mathrm{mA} \mathrm{cm}^{-2}\right)$ & $V_{\mathrm{oc}}(\mathrm{V})$ & $\mathrm{FF}$ & PCE $(\%)^{\text {Ref }}$ \\
\hline $\mathrm{PEI} / \mathrm{Y}-\mathrm{TiO}_{2}$ & ITO/PEIE/ $\mathrm{CH}_{3} \mathrm{NH}_{3} \mathrm{PbICl} /$ Spiro-OMeTAD/Au & 22.75 & 1.13 & 0.750 & 19.03 (ref. 71) \\
\hline $\mathrm{PEI} / \mathrm{N}: \mathrm{ZnO}$ & $\mathrm{ITO} / \mathrm{ZnO} / \mathrm{PEI} / \mathrm{CH}_{3} \mathrm{NH}_{3} \mathrm{PbI}_{3} / \mathrm{SpiroOMeTAD} / \mathrm{Au}$ & 21.5 & 9.645 & 0.700 & 16.1 (ref. 107) \\
\hline $\mathrm{ZnO} / \mathrm{PCBM}$ & ITO/PEDOT:PSS/ $\mathrm{CH}_{3} \mathrm{NH}_{3} \mathrm{PbI}_{3-x} \mathrm{Cl}_{x} / \mathrm{PCBM} / \mathrm{ZnO} / \mathrm{Ag}$ & 16.0 & 0.95 & 0.745 & 11.3 (ref. 145) \\
\hline Perylene-diimide/PCBM & ITO/PEDOT:PSS/CH $\mathrm{CH}_{3} \mathrm{PbI}_{3-x} \mathrm{Cl}_{x} / \mathrm{PCBM} / \mathrm{PDINO} / \mathrm{Ag}$ & 18.8 & 0.95 & 0.785 & 14.0 (ref. 145) \\
\hline PEI/PCBM & $\mathrm{FTO} / \mathrm{PEI} / \mathrm{PCBM} / \mathrm{MAPbI}_{3} / \mathrm{PTAA} / \mathrm{Au}$ & 21.8 & 0.98 & 0.720 & 15.3 (ref. 138 ) \\
\hline Rhodamine $101 / \mathrm{LiF}$ & ITO/PEDOT:PSS/CH${ }_{3} \mathrm{NH}_{3} \mathrm{PbI}_{3-x} \mathrm{Cl}_{x} /$ rhodamine $101 / \mathrm{LiF} / \mathrm{Ag}$ & 17.72 & 1.01 & 0.730 & 13.2 (ref. 134 ) \\
\hline PCBM:polystyrene & $\left.\mathrm{FTO} / \mathrm{NiO} / \mathrm{CH}_{3} \mathrm{NH}_{3} \mathrm{PbI}_{3-x} \mathrm{Cl}_{x} / \mathrm{PCBM}: \mathrm{PS}\right) / \mathrm{Al}$ & 15.62 & 1.07 & 0.640 & 10.68 (ref. 39) \\
\hline PN4N & ITO/PEDOT:PSS/CH${ }_{3} \mathrm{NH}_{3} \mathrm{PbI}_{3-x} \mathrm{Cl}_{x} / \mathrm{PCBM} / \mathrm{PN} 4 \mathrm{~N} / \mathrm{Al}$ & 20.61 & 1.0 & 0.725 & 15 (ref. 146) \\
\hline PFN & ITO/PEDOT:PSS/CH${ }_{3} \mathrm{NH}_{3} \mathrm{PbI}_{3-x} \mathrm{Cl}_{x} / \mathrm{PCBM} / \mathrm{PFN} / \mathrm{Al}$ & 20.47 & 0.98 & 0.552 & 8.7 (ref. 146) \\
\hline
\end{tabular}

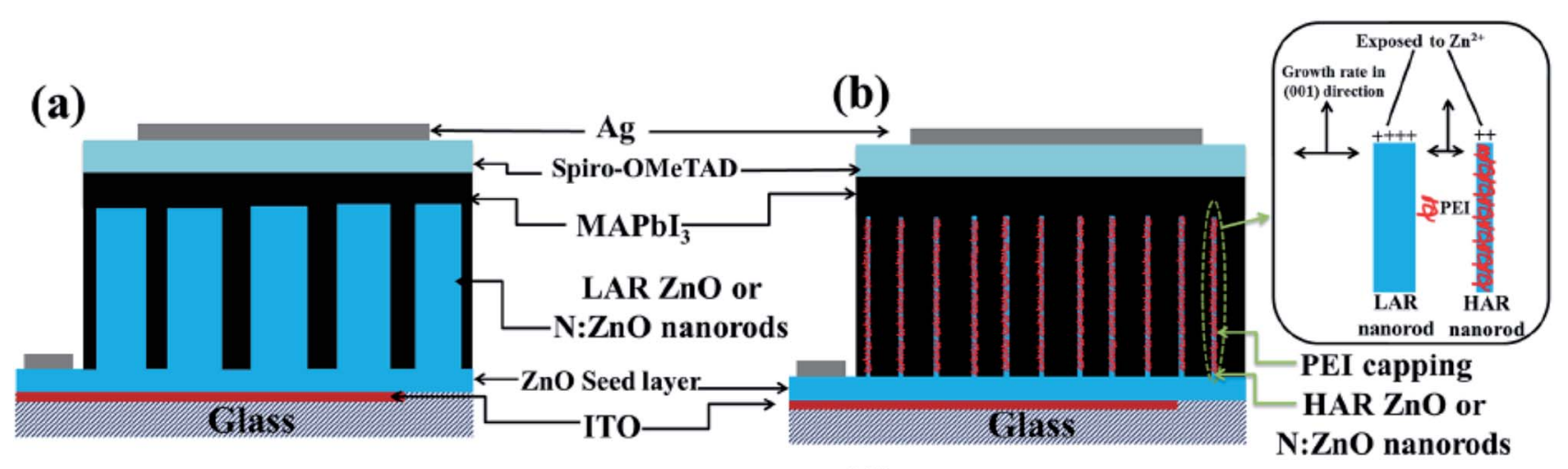

(c)

(d)
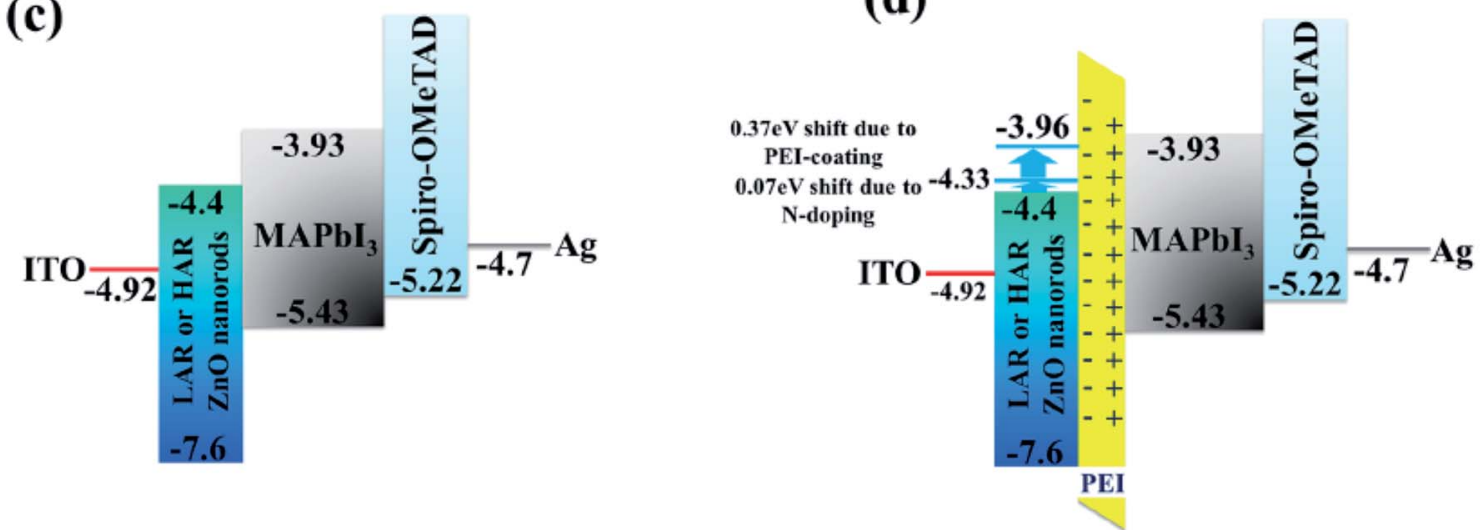

Fig. 15 Schematics of device structure based on (a) conventional low aspect ratio (LAR) NR arrays, and (b) high aspect ratio (HAR) NR arrays with additional PEI coating (the inset shows the schematic representation of PEI as a capping agent to control nanorod growth). Energy diagrams of the devices based on (c) LAR or HAR NRs without PEI coating and (d) LAR or HAR NRs with PEI coating. The conduction band energy of ZnO was lowered by $0.07 \mathrm{eV}$ by nitrogen doping and by $0.37 \mathrm{eV}$ by dipole formation by the PEl layer. ${ }^{107}$ 


\section{3g. Nanostructured electron transport layer}

Surface coverage of the perovskite layer by the ETL is one of several issues in PSCs. Compact $\mathrm{TiO}_{2}$ deposited by ALD or a spincoated $\mathrm{m}-\mathrm{TiO}_{2}$ compact layer is better for vapour-deposited perovskite layer, as reported by Snaith's group for planar heterojunction (PHJ) PSC. Chlorine inclusion or chlorine addition in either a one-step or two-step method gives better surface coverage on $\mathrm{m}-\mathrm{TiO}_{2}$. This technique provides the PHJ PSC. However, a nanostructured ETL has been found to be best for iodine precursor or mixed halide precursors in which the perovskite crystal is in the range $200-500 \mathrm{~nm}$. Controlling the aspect ratio of nanowires allows perovskite to infiltrate into the ETL, giving a direct path for the charge carrier to be collected by the electrode.

Generally, the PSC needs a mesoporous ETL, compact ETL, or a scaffold material for growth of the perovskite absorber. The most common practice is to use a commercially available mesoporous $\mathrm{TiO}_{2}$ layer, which has superior electrical properties because the mesoporous $\mathrm{TiO}_{2}$ is deposited easily by spincoating, but the thickness and roughness cannot be easily controlled. Also, perovskite is sometimes inserted into the $\mathrm{TiO}_{2}$ layer and this cannot be distinguished using a cross-sectional scanning electron microscope. A number of reports describe such intermixed $\mathrm{TiO}_{2}$ and perovskite layers using the $1 \mathrm{~S}$ and $2 \mathrm{~S}$ methods. The microstructure of $\mathrm{CH}_{3} \mathrm{NH}_{3} \mathrm{PbI}_{3}$ has particle size in the range of 100-500 $\mathrm{nm}$ with large pore size. When the HTM is deposited on the perovskite layer, the HTL may insert into the gaps, touching the ETL and providing a shunt path. Consequently, the efficiency of the solar cell is degraded. The effects of morphology and pore filling of mesoporous $\mathrm{TiO}_{2}$ layer and perovskite layer in terms of device performance were studied by Nanova et al. ${ }^{69}$ TEM-EELS (electron energy loss spectroscopy) measurements were used to study the mechanism and optimum pore structure of $\mathrm{TiO}_{2} /$ perovskite. A finer grain of $\mathrm{TiO}_{2}$ efficiently accompanies the perovskite, resulting in an interlinked structure and better PCE. Hence, an over-layer perovskite absorber is needed to overcome the problems described above (Fig. 16).

Fast electron transport and charge collection is possible using nanostructured ETL materials such as nanowire, nanosheets, and nanoneedles. These NSs provide better charge
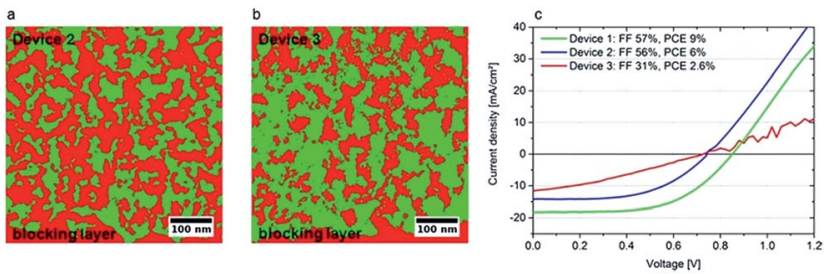

Fig. 16 Correlation between morphology and device characteristics. (a) Device 2 exhibits a compact and well-connected $\mathrm{TiO}_{2}$ network. (b) The $\mathrm{TiO}_{2}$ in device 3 is a much finer grained structure (very small and unconnected red domains). (c) $I-V$ characteristics of the devices. The higher fill factors of devices 1 and 2 can be correlated to the wellconnected $\mathrm{TiO}_{2}$ network and hence better electron transport properties. ${ }^{66}$ injection and unidirectional charge transport. Smooth injection is the key point at the ETL and perovskite interface, which must satisfy the condition that the LUMO of the ETL is lower than that of the perovskite. However, the $\mathrm{CH}_{3} \mathrm{NH}_{3} \mathrm{PbI}_{3}$ and $(\mathrm{Cl}, \mathrm{Br})$ doped $\mathrm{CH}_{3} \mathrm{NH}_{3} \mathrm{PbI}_{3}\left(\mathrm{CH}_{3} \mathrm{NH}_{3} \mathrm{PbCl}_{x}, \mathrm{CH}_{3} \mathrm{NH}_{3} \mathrm{PbCl}_{x} \mathrm{Br}_{y} \mathrm{I}_{1-y}\right)$ were found to be beneficial because of the optimum band gap giving broad absorption in the UV-Vis region and high extinction coefficient. ${ }^{113-115}$ A schematic band energy level diagram of hybrid perovskite materials is presented in Fig. 1. To provide a smoother path for the electron the LUMO level of the ETL should be lower than the LUMO level of the intrinsic layer, and the HOMO level should be higher than that of the intrinsic layer.

Nanostructure ETL such as nanowire and nanorods were found to be beneficial for charge collection. A better surface morphology, roughness, and nanoarchitecture give efficient electron injection and a short carrier path for the electron. Transition metal oxides $\left(\mathrm{TiO}_{2}, \mathrm{ZnO}\right)$ can have a variety of nanostructures, and can be easily doped by a number of elements to increase/decrease the Fermi level, which affects the electron injection efficiency and consequently leads to enhanced transport properties and better charge collection efficiency. Park et al. used $\mathrm{ZnO}$ nanorods to efficiently collect the electron from the lower wavelength region. ${ }^{46}$

Using a dense compact $\mathrm{TiO}_{2}$ layer, the series resistance of photovoltaics (PV) was improved by Ke et al. ${ }^{116}$ Their approach was to minimize the series resistance, giving a higher recombination time of the PSC. They achieved about $15.07 \%$ efficiency with $V_{\text {oc }}$ up to $1.04 \mathrm{~V}$. Using electrospun deposited $\mathrm{TiO}_{2}$ nanofibre of different $\mathrm{TiO}_{2}$ thicknesses, Dharani et al. reported $V_{\mathrm{oc}}=$ $844 \mathrm{mV}$ with $\mathrm{PCE}=9.8 \% .^{50}$ They predicted that $V_{\mathrm{oc}}$ decreased with increasing fibre thickness.

Hydrothermally deposited one-dimensional $\mathrm{TiO}_{2}$ array rather than a mesoporous $\mathrm{TiO}_{2}$ layer is a better ETL for PSC. A schematic of a $1 \mathrm{D} \mathrm{TiO}_{2} /$ perovskite solar cell is presented in Fig. 17. ${ }^{50}$ The schematic gives misleading information that the HTL is in contact with the $\mathrm{TiO}_{2}$ ETL, which might have resulted in high shunt resistance and low recombination time, so degrading the solar cell performance. Hence, the $J-V$ curves did not maintain the current with increasing $V_{\mathrm{oc}}$. At the same time the series resistance is comparatively high using long $\mathrm{TiO}_{2}$ nanorod. A highly efficient $1 \mathrm{D} \mathrm{TiO}_{2}$ can be fabricated by proper choice of thickness of $\mathrm{TiO}_{2}$ and doped $\mathrm{TiO}_{2}$ nanorod with excellent pore filling and over layer perovskite material with controlled pore size. Large pore size and particle size of perovskite films allow insertion of the HTL into the $\mathrm{TiO}_{2}$ ETL, giving low shunt resistance which gives low $\mathrm{FF}$.

Control over nanostructure ETL with different morphology and size shows better electron injection, electron transfer, and charge collection efficiency. ${ }^{36,37,100}$ The thickness and gap between nanorods should be controlled to decrease the series resistance and increase the shunt resistance. A non-porous ETL needs a thin compact hole blocking layer for better film growth. Increasing the nanowire length provides higher series resistance and also gives a large carrier path to extract the electron. If the nanowire size can be controlled, the perovskite can be infiltrated into the nanowire gaps, which would compensate the 

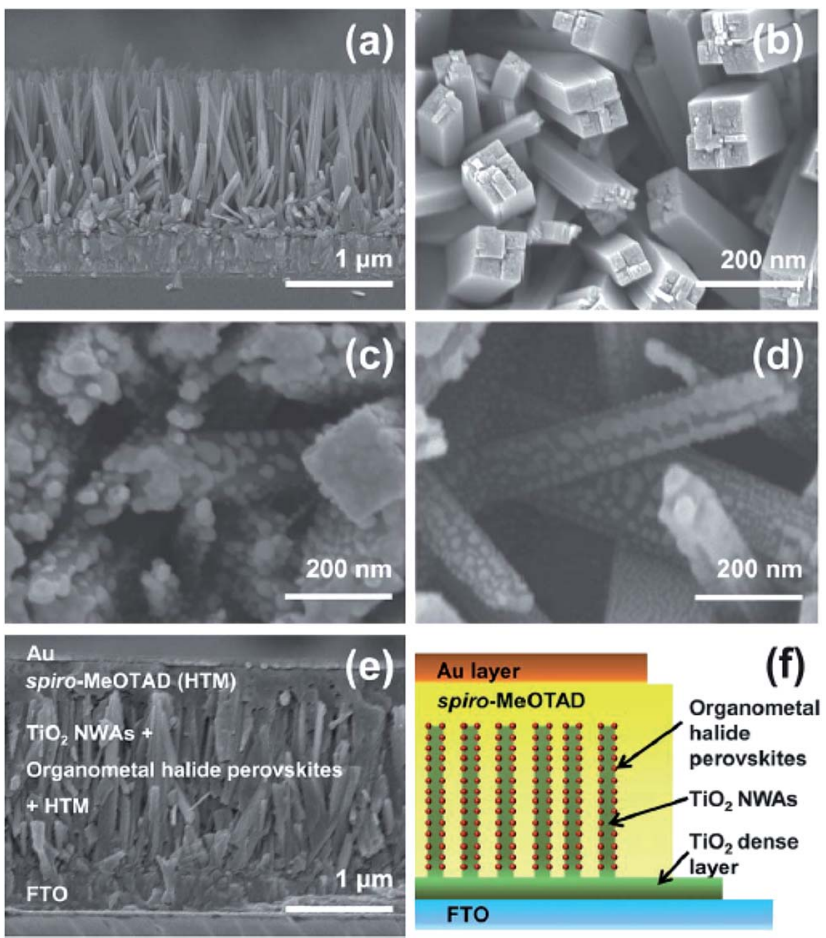

Fig. 17 Cross-sectional (a) and top (b) view SEM images of $\mathrm{TiO}_{2}$ nanowire arrays (NWAs) synthesized on FTO substrates. SEM images of $\mathrm{CH}_{3} \mathrm{NH}_{3} \mathrm{Pbl}_{2} \mathrm{Br}$ (c) and $\mathrm{CH}_{3} \mathrm{NH}_{3} \mathrm{Pbl}_{3}$ (d) spin-coated on $\mathrm{TiO}_{2} \mathrm{NWAs}$. (e) Cross-sectional SEM image of the $\mathrm{TiO}_{2}$ NWAs/perovskite sensitizer/ spiro-MeOTAD hybrid photovoltaic cell. (f) Schematic illustration of the hybrid solar cell.

series resistance by several orders. At the same time, a proper morphology must be considered to obtain high efficiency. The microstructure cannot be easily controlled using the spin coating process. Extra additives or doping is required to initiate a large number of nucleation sites which can grow nanocrystalline perovskite nanoparticles with high surface coverage. This method allows high shunt resistance to get high fill factor with high external quantum efficiency (EQE).

By controlling the photoelectrode thickness and perovskite thickness, Dhar et al. efficiently controlled the charge injection to the photoelectrode. A PSC of $12 \%$ efficiency was fabricated using novel (001)-oriented nanoplatelets of anatase thin film as the photoanode.$^{117} \mathrm{~A}$ thicker ETL material provides a longer diffusion path for the electron to reach the electrode, which limits the charge collection efficiency and also transmittance of the incident photon decreases with increasing thickness. So when designing an ETL, the optimum thickness should be considered. Oh et al. reported ternary $\mathrm{Zn}_{2} \mathrm{SnO}_{4}$ (ZSO) as the electrontransporting electrode of a $\mathrm{CH}_{3} \mathrm{NH}_{3} \mathrm{PbI}_{3} \mathrm{PSC}$ as an alternative to the conventional $\mathrm{TiO}_{2}$ electrode. ${ }^{118-120}$ They obtained different thicknesses of ZSO compact layer or ZSO mesoscopic layer using the spin coating method. ${ }^{118}$ They observed that transmittance of ZSO films had negligible effect on increasing thickness. In addition, time-resolved and frequency-resolved measurements revealed that the ZSO-based PSC exhibits faster electron transport ( $\sim 10$ times) and superior charge collection capability compared

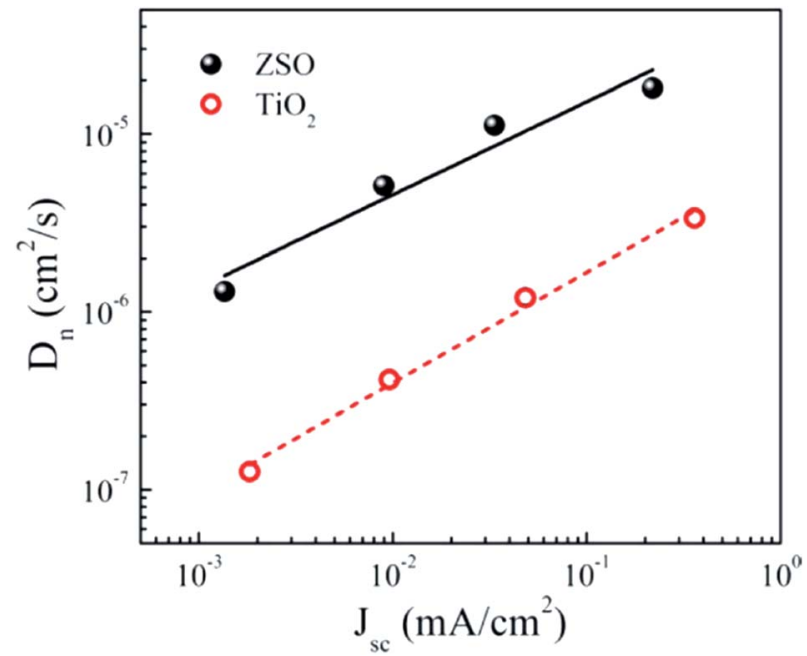

Fig. 18 Electron diffusion coefficients of the ZSO-based perovskite solar cell with the highest conversion efficiency. Electron diffusion coefficients of $\mathrm{TiO}_{2}$-based perovskite solar cell with similar thickness $(\sim 300 \mathrm{~nm})$ and conversion efficiency $(\sim 7 \%)$ are also presented for a comparison. ${ }^{118}$

with its $\mathrm{TiO}_{2}$-based counterpart with similar thickness and conversion efficiency. Using $\mathrm{Zn}_{2} \mathrm{SnO}_{4} / \mathrm{PVP}$ nanofibres, Mali et al. reported $7.3 \%$ efficiency (Fig. 18).

\section{3h. Additive controlled enhanced charge injection/ collection}

Wang et al. ${ }^{121}$ used a range of additives from divalent (II), trivalent (III), and tetravalent (Iv) to hexavalent (vI) acetylacetonate in $\mathrm{TiO}_{2}$ to demonstrate efficient charge injection. Also, different substrate treatment of $\mathrm{m}-\mathrm{TiO}_{2}$ was found to be beneficial for crystallization behaviour of the perovskite layer. ${ }^{117}$ Amino acid-modified $\mathrm{TiO}_{2}$ ETM has more efficient charge transfer from perovskite to $\mathrm{TiO}_{2} \cdot{ }^{122}$

Using ZnO/PCBM ETL in a PHJ PSC, trap-assisted recombination was lowered by several orders. ${ }^{123}$ Interface modification plays a crucial factor by passivation or deposition of polymer on inorganic ETL, found to enhance the efficiency of PSC by improving the electron transport/extraction. The aim of using PCBM on $\mathrm{ZnO}^{123}$ and $\mathrm{TiO}_{2}$ (ref. 124 and 125) is to adjust the quasi Fermi level of ETL and HTL, as the $V_{\text {oc }}$ of the PHJ PSC is decided by the energy-level offset between the quasi Fermi levels of the ETM and the HTL adjacent to the perovskite active layer. ${ }^{126,127}$ In addition, efficiency can also be enhanced by use of an induced dipole moment to enhance charge collection of electron and reduce charge recombination (Fig. 19).

The role of the ETM/ETL is to collect electrons efficiently and retard the hole toward the HTL. Efficient charge injection of electron or hole can be analysed by time-resolved photoluminescence decays and the photoluminescence quantum efficiencies of the perovskite films on ETL. With a BHJ PSC architecture, using $\mathrm{PC}_{61} \mathrm{BM} / \mathrm{CH}_{3} \mathrm{NH}_{3} \mathrm{PbI}_{3}: \mathrm{PC}_{61} \mathrm{BM}$ composite thin films, the device performance was improved by means of excellent charge collection. Fig. 21 shows the photoluminescence (PL) spectra of the pristine $\mathrm{CH}_{3} \mathrm{NH}_{3} \mathrm{PbI}_{3}, \mathrm{CH}_{3} \mathrm{NH}_{3} \mathrm{PbI}_{3}: \mathrm{PC}_{61} \mathrm{BM}$, 

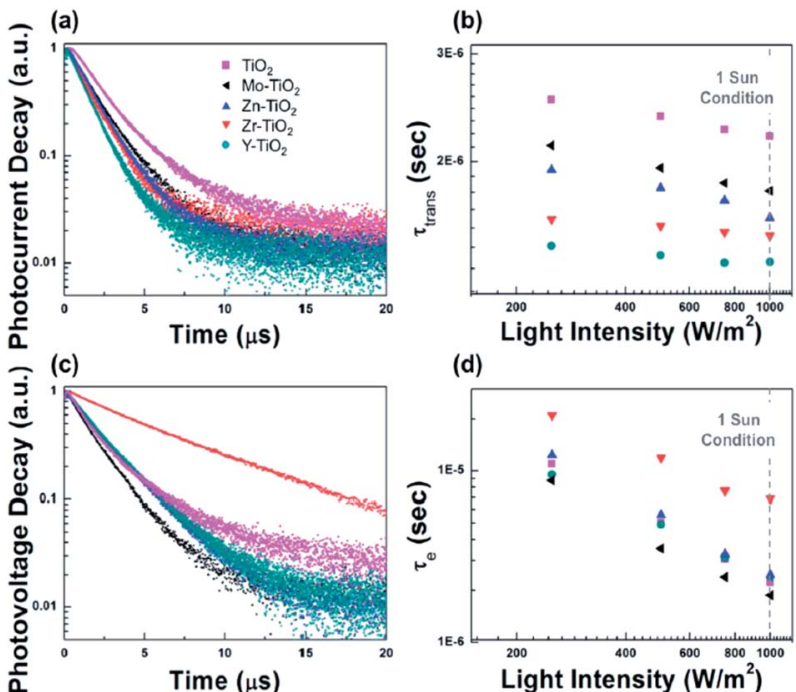

(d)

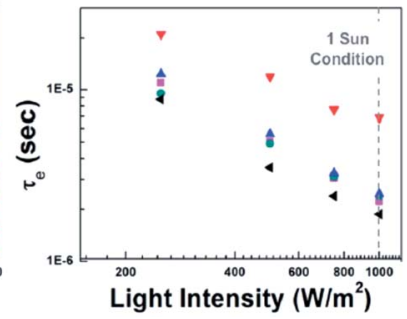

Fig. 19 (a and c) Photocurrent and photovoltage decay of devices employing the $\mathrm{TiO}_{2}$ ETL incorporated with different acetylacetonatebased additives and ( $b$ and $d$ ) the related carrier transport lifetime and electron lifetime. Intensity is shown in log scale and 1 sun condition is equivalent to $1000 \mathrm{~W}^{121}$

and $\mathrm{PC}_{61} \mathrm{BM} / \mathrm{CH}_{3} \mathrm{NH}_{3} \mathrm{PbI}_{3}: \mathrm{PC}_{61} \mathrm{BM}$ thin films. PL quenching was observed in $\mathrm{CH}_{3} \mathrm{NH}_{3} \mathrm{PbI}_{3}: \mathrm{PC}_{61} \mathrm{BM}$ and $\mathrm{PC}_{61} \mathrm{BM} / \mathrm{CH}_{3} \mathrm{NH}_{3} \mathrm{PbI}_{3}$ :- $^{-}$ $\mathrm{PC}_{61} \mathrm{BM}$ composites compared with $\mathrm{CH}_{3} \mathrm{NH}_{3} \mathrm{PbI}_{3}$, which confirms efficient exciton dissociation at "donor/acceptor" interfaces and subsequently electron extraction. With this concept, reduced electron-hole pair recombination and faster charge extraction/collection was obtained in the conventional BHJ PSCs. ${ }^{124}$ At the same time, this composite film shows higher absorbance than the $\mathrm{CH}_{3} \mathrm{NH}_{3} \mathrm{PbI}_{3}$ (Fig. 20-22).

\section{3i. Plasmonic nanoparticles in conventional electron transport layer}

Plasmonic NPs improve absorption by scattering light using metal nanoparticles excited at their surface plasmon resonance. Using sandwiched $\mathrm{TiO}_{x}-\mathrm{Au}-\mathrm{TiO}_{x}$ ETL with a plasmon-mediated hot carrier injection from the Au-NPs to $\mathrm{TiO}_{x}$, Yuan achieved PCE of $16.2 \% .{ }^{129}$ Using binary $\mathrm{Au}-\mathrm{Ag}$ popcorn metal NPs, absorption of both $\mathrm{TiO}_{2}$ and perovskite active layer improves through localized surface plasmon (LSP), which gives higher efficiency (Fig. 23). ${ }^{\mathbf{1 3 0}}$

In a similar way, a DMAPA-C 60 layer on PCBM lowers the work function (WF) by inducing an interface dipole moment, creating a selective quasi-ohmic contact at the interface with Ag (Fig. 24). ${ }^{131}$ This formation of a dipole layer by either PEI or DMAPA- $\mathrm{C}_{60}$ directly impacts on the WF of electrode and suppresses the energy barrier between the ETL and electrode. ${ }^{\mathbf{1 0 4}}$

A remarkable $\mathrm{FF}$ of $86.7 \%$ with enhanced electron extraction efficiency was achieved by bulk heterojunction (BHJ) pero-HSCs fabricated by blending perovskite materials with fullerene derivatives $\mathrm{A}_{10} \mathrm{C}_{60}$ (Fig. 25). ${ }^{\mathbf{1 3 2}}$

Limitation of the band gap and absorbance in the UV-Vis region and their photoresponses limits the device performance.
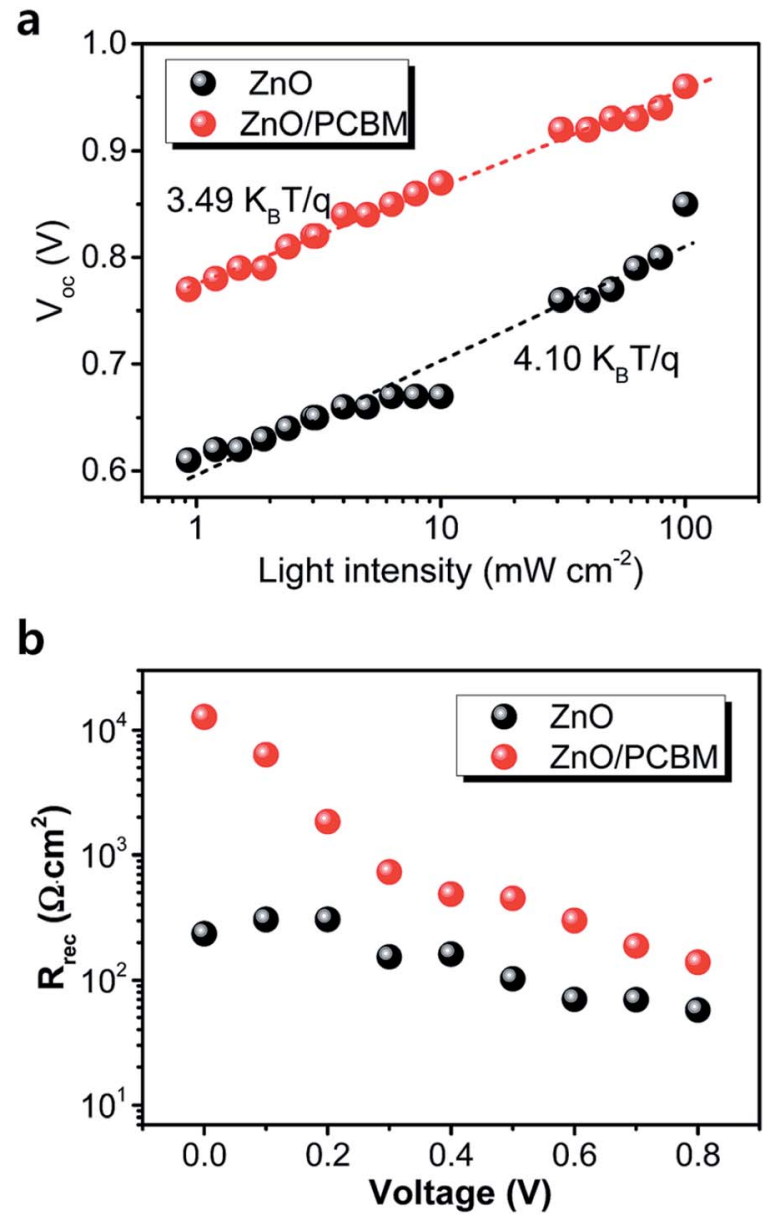

Fig. 20 (a) Light-intensity dependence of the $V_{\text {oc }}$ of the perovskite solar cells with $\mathrm{ZnO}$ and $\mathrm{ZnO} / \mathrm{PCBM}$. The lines represent the best fits to the data, for which the slope is indicated. (b) Recombination resistance at different applied biases extracted from IS characterization of the perovskite solar cells. ${ }^{128}$

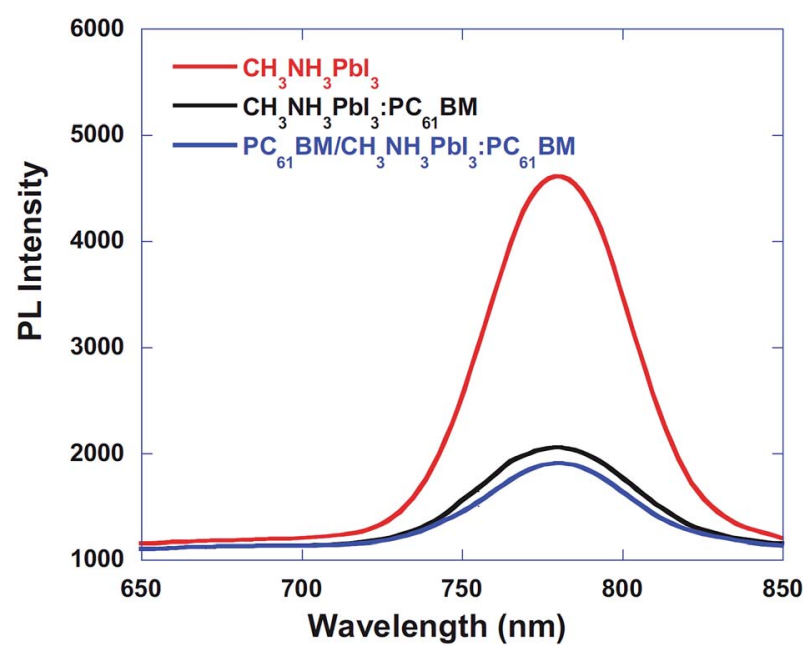

Fig. 21 Photoluminescence $(\mathrm{PL})$ spectra of the pristine $\mathrm{CH}_{3} \mathrm{NH}_{3}$ $\mathrm{Pbl}_{3}, \mathrm{CH}_{3} \mathrm{NH}_{3} \mathrm{Pbl}_{3}: \mathrm{PC}_{61} \mathrm{BM}$, and $\mathrm{PC}_{61} \mathrm{BM} / \mathrm{CH}_{3} \mathrm{NH}_{3} \mathrm{Pbl}_{3}: \mathrm{PC}_{61} \mathrm{BM}$ thin films. ${ }^{124}$ 


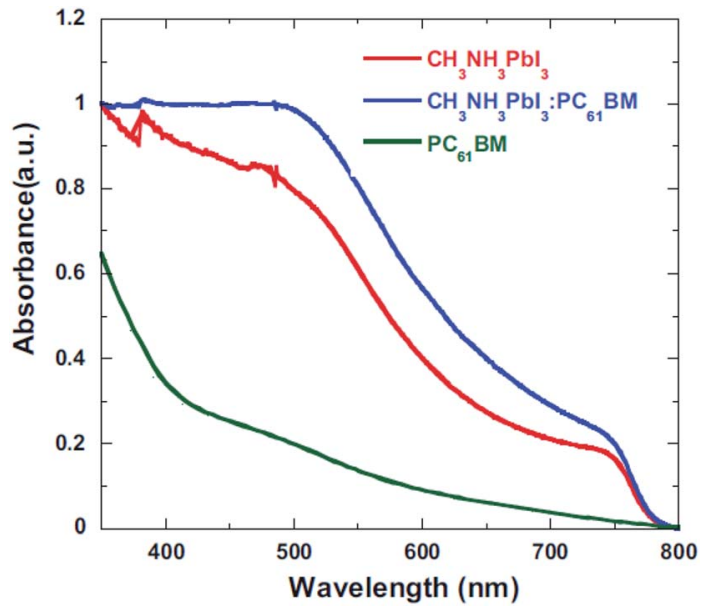

Fig. 22 Absorption spectroscopy of $\mathrm{CH}_{3} \mathrm{NH}_{3} \mathrm{Pbl}_{3}, \mathrm{CH}_{3} \mathrm{NH}_{3} \mathrm{Pbl}_{3}: \mathrm{PC}_{61}-$ $\mathrm{BM}$, and $\mathrm{PC}_{61} \mathrm{BM} / \mathrm{CH}_{3} \mathrm{NH}_{3} \mathrm{Pbl}_{3}: \mathrm{PC}_{61} \mathrm{BM}$ thin films. ${ }^{124}$
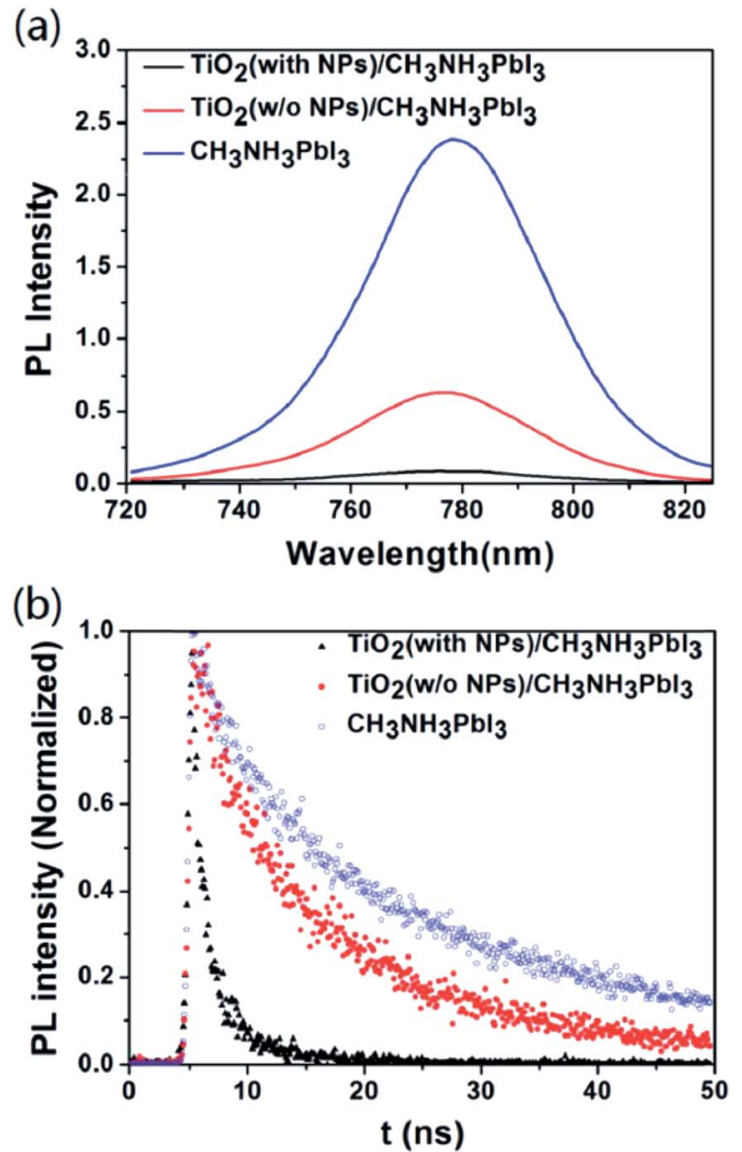

Fig. 23 (a) Photovoltaic performance of 25 individual devices (red: devices with popcorn NPs; black: control devices). (b) J-V curves of the best-performance perovskite device with and without popcorn NPs, respectively. ${ }^{130}$

It has been confirmed that the band gap of $\mathrm{MAMeX}_{3}$ can be tuned by changing M, A, Me, X, or MA; however, devices suffer in terms of $J_{\mathrm{sc}}, V_{\mathrm{oc}}$, and FF. By implementing another photoactive material in a PSC, which could behave as both ETL and active material, better performance would be achieved than using a material with single active layer. Poly(diketopyrrolopyrrole-terthiophene) (PDPP3T) is a typical low-band gap polymer which is used as an active material in PSCs. It also has lower HOMO level than that of hybrid perovskite material, enabling use as the ETL in PHJ or $\mathrm{BHJ}$ solar cell. ${ }^{133}$ By implanting PDPP3T-PC ${ }_{61} \mathrm{BM} \mathrm{BHJ}$ into PSCs, the absorbance of a cell was successfully enhanced in the longwavelength region. Fig. 26 shows a comparison of absorbance of $\mathrm{CH}_{3} \mathrm{NH}_{3} \mathrm{PbI}_{3} /\left(\mathrm{PDPP} 3 \mathrm{~T}-\mathrm{PC}_{61} \mathrm{BM}\right)$ blend films (Fig. 26).

Even when the band energy level of PCBM matches with cathode, some interfacial issues can arise such as interfacial trap and defect states, which significantly affect the charge collection. Interlayer polymers can overcome these difficulties and help to achieve smooth energy level alignment. These polymers can help electrons to efficiently collect at the cathode of PSCs in cases of energy mismatch between PCBM and cathode. In addition, interlayers can provide better surface roughness for electrode deposition, which ultimately affects the charge collection. It is believed that polymer ETL passivates defects of the perovskite layer, which might not occur when using inorganic ETL/scaffold. Another advantage of polymer ETL is that it does not require high temperature deposition.

In general, a compact $\mathrm{TiO}_{2}$ layer is used as the hole blocking layer (HBL) in $\mathrm{m}^{-\mathrm{TiO}_{2}}$ based PSCs. The BCP layer on PCBM ETL acts in the same way as the $\mathrm{TiO}_{2}$ compact layer does in inorganic ETL. By employing double interfacial layers (rhodamine101/ LiF), Sun et al. achieved better efficiency than that of PCBM/ LiF and PCBM/rhodamine 101. ${ }^{134}$ Moreover, zwitterions with positive and negative charges on the same molecule can lower the work function of electrodes by formation of interface dipoles. ${ }^{\mathbf{1 3 5 , 1 3 6}}$ In the same way, this was achieved using interlayer PEI on $\mathrm{TiO}_{2}$ [Yang] or $\mathrm{ZnO}$ [Mahmood].

The addition of PS aids formation of a highly smooth and uniform PCBM on the perovskite active layer that is more effective in preventing undesirable electron-hole recombination between the perovskite layer and the top electrode. ${ }^{39}$

\section{3j. Functionalization}

By introducing glycine, an amino acid, as a coupling agent, better surface morphology of perovskite films was observed, which ultimately reduced the transport resistance (Fig. 28) and improved the $J_{\text {sc }}$ from 14.42 to $19.54 \mathrm{~mA} \mathrm{~cm}^{-2}$ (Fig. 27). ${ }^{137}$

Conjugated polymer electrolytes (CPEs) are another class of efficient interface materials that form the electron dipole moment at the interface of either metal/ETL or ETL/perovskite. These concepts of interface engineering have been regarded as beneficial for improving the device performance by charge collection, extraction/injection. Ryu et al. achieved PCE of about 15\% in FTO/ PEI/PCBM/MAPbI ${ }_{3} / \mathrm{PTAA} / \mathrm{Au}$ PHJ PSC. ${ }^{\mathbf{1 3 8}}$ To improve efficiency, well-organized mesoporous $\mathrm{TiO}_{2}$ photoelectrodes were fabricated by block copolymer-induced sol-gel assembly by Sarkar et al. ${ }^{139}$

$V_{\text {oc }}$ can be increased by reducing electron-hole recombination occurring at the HTL/ETL inside a perovskite pinhole. Functionalizing the ETL/scaffold by organic/polymer molecules would provide better recombination resistance. Different concentrations of 3-aminopropyl (3-oxobutanoic acid) 


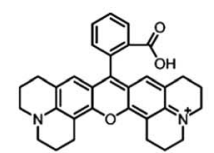

rhodamine 101

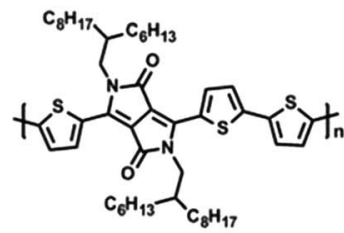

PDPP3T

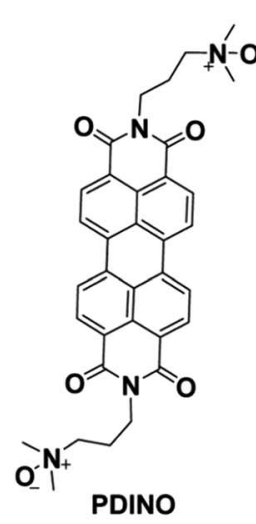

PDINO<smiles>CCCN(CCN)CCNCCN(CCNCCN)CCN(CCN)CCN(CCN)CCN</smiles>

Polyethyleneimine

Fig. 24 Different polymer additives used in organic electron transport layers. ${ }^{131}$
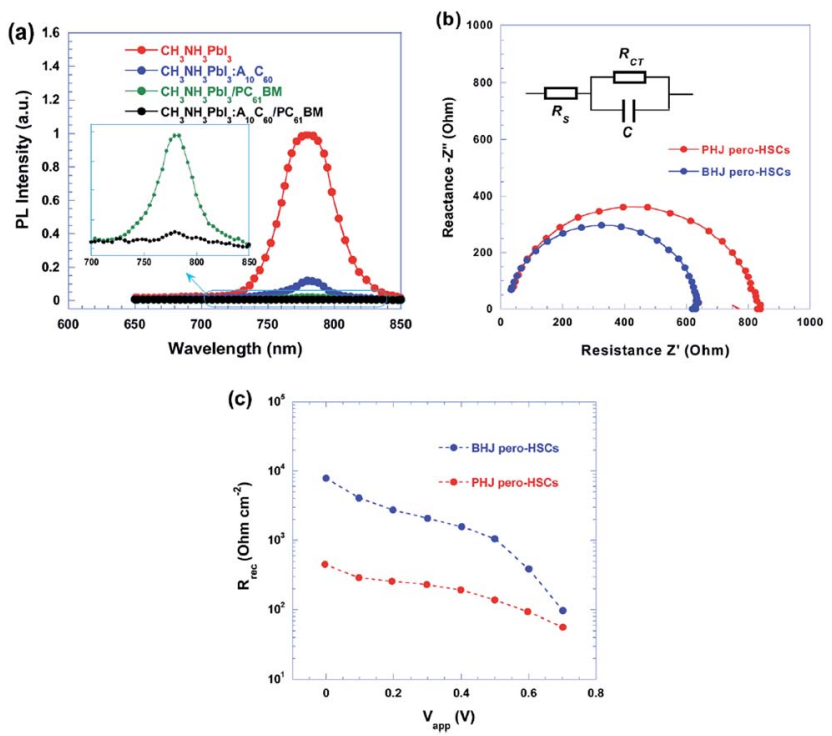

Fig. 25 (a) $\mathrm{PL}$ spectra of $\mathrm{CH}_{3} \mathrm{NH}_{3} \mathrm{Pbl}_{3}, \mathrm{CH}_{3} \mathrm{NH}_{3} \mathrm{Pbl}_{3}: \mathrm{A}_{10} \mathrm{C}_{60}, \mathrm{CH}_{3}$ $\mathrm{NH}_{3} \mathrm{Pbl}_{3} / \mathrm{PC}_{61} \mathrm{BM}$ and $\mathrm{CH}_{3} \mathrm{NH}_{3} \mathrm{Pbl}_{3}: \mathrm{A}_{10} \mathrm{C}_{60} / \mathrm{PC}_{61} \mathrm{BM}$ thin films; insets, enlarged $\mathrm{PL}$ spectra of $\mathrm{CH}_{3} \mathrm{NH}_{3} \mathrm{Pbl}_{3} / \mathrm{PC}_{61} \mathrm{BM}$ and $\mathrm{CH}_{3} \mathrm{NH}_{3} \mathrm{Pbl}_{3}: \mathrm{A}_{10} \mathrm{C}_{60} /$ $\mathrm{PC}_{61} \mathrm{BM}$ thin films. (b) Nyquist plots of $\mathrm{PHJ}$ and $\mathrm{BHJ}$ pero-HSCs measured in the dark and at an applied voltage close to the opencircuit voltage of the pero-HSCs. (c) Recombination resistance resulting from impedance spectrometry measurements fitted for different applied biases at 1 sun illumination. ${ }^{132}$

functionalized silica nanoparticles were used to improve $V_{\text {oc }}$ and PCE by a one-step solution process. ${ }^{140}$ The advantage of functionalized $\mathrm{SiO}_{2} \mathrm{NPs}$ over compact $\mathrm{TiO}_{2}$, is that hole transfer is hindered from the perovskite as well as the HTL. The functionalized $\mathrm{SiO}_{2}$ lowers the conduction band edge to give a smooth electron injection to the metal electrode. Absorption of perovskite films was improved in a broad range of light spectrum by employing 3-aminopropyl (3-oxobutanoic acid) functionalized silica nanoparticles at different concentrations, as shown in Fig. 29.

$\mathrm{C}_{60} \mathrm{SAM}$ functionalized mesoporous $\mathrm{TiO}_{2}$ as ETL has shown recorded efficiency of $\sim 11.7 \%$ in a perovskite-sensitized solar cell using Spiro-OMeTAD as a transparent hole transporter. ${ }^{141}$

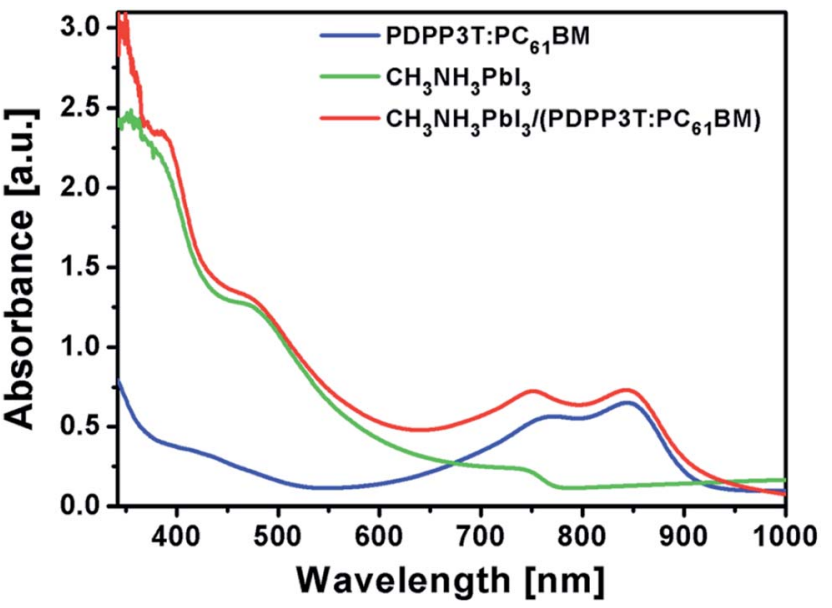

Fig. 26 Comparison of absorption spectra for PDPP3T-PC ${ }_{61} \mathrm{BM}(1: 2)$ blend film, $\mathrm{CH}_{3} \mathrm{NH}_{3} \mathrm{Pbl}_{3}$ film, and $\mathrm{CH}_{3} \mathrm{NH}_{3} \mathrm{Pbl}_{3} /\left(\mathrm{PDPP} 3 \mathrm{~T}-\mathrm{PC}_{61} \mathrm{BM}\right.$ ) $(1: 2)$ bilayer film. ${ }^{133}$

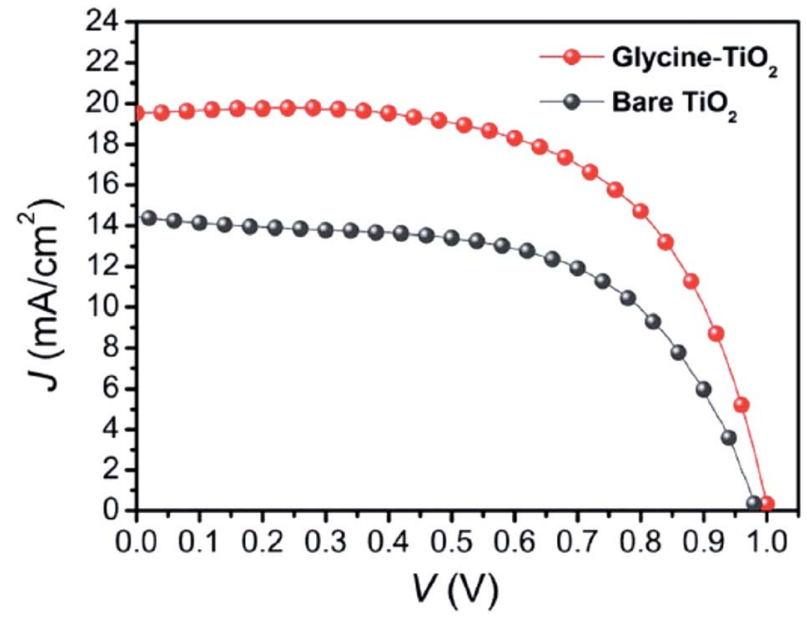

Fig. $27 \mathrm{~J}-V$ curves of the best perovskite solar cells with bare $\mathrm{TiO}_{2}$ (dark gray curve) and glycine-treated $\mathrm{TiO}_{2}$ (red curve). ${ }^{137}$ 


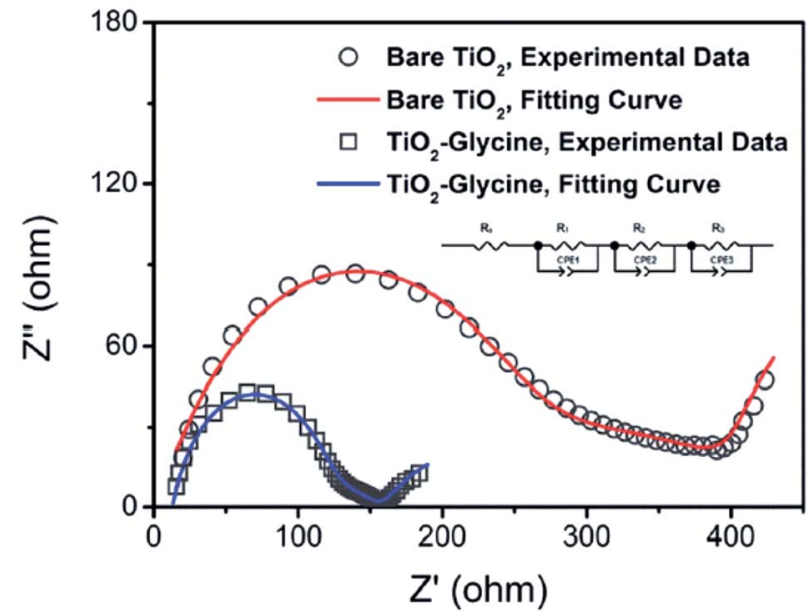

Fig. 28 Nyquist plots of perovskite solar cells based on bare $\mathrm{TiO}_{2}$ (symbol B) and glycine-treated $\mathrm{TiO}_{2}$ (symbol). Symbols are experimental data and solid lines correspond to the fitting results using the equivalent circuit shown in the inset figure. EIS spectra were recorded using a potentiostat/galvanostat instrument (PGSTAT 302N Autolab) equipped with a FRA2 module under constant light illumination of $100 \mathrm{~mW} \mathrm{~cm}{ }^{2}$. A DC applied bias voltage was set at open circuit voltage of the perovskite solar cells with a sinusoidal ac potential perturbation of $15 \mathrm{mV}$ over a frequency range from $1 \mathrm{MHz}$ to $0.01 \mathrm{~Hz} .^{137}$

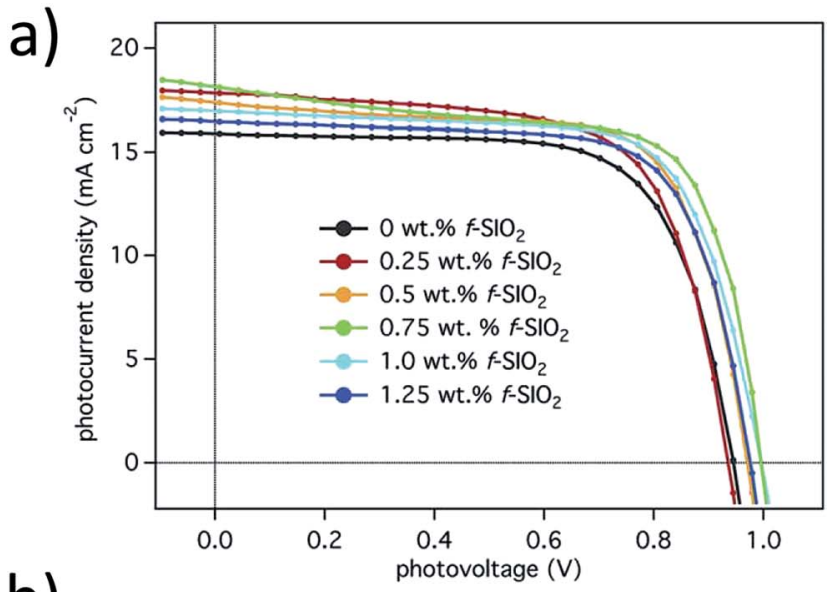

b)

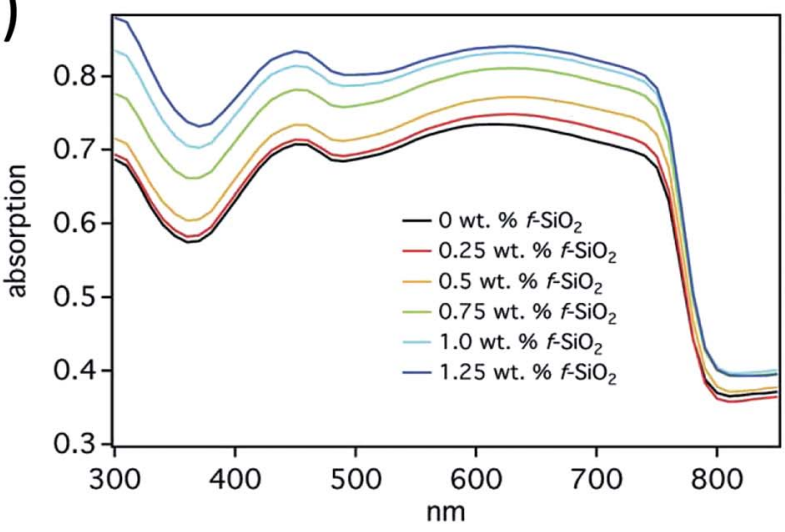

Fig. 29 (a) I-V curves of best performing devices for each $\mathrm{f}-\mathrm{SiO}_{2} \mathrm{wt} \%$; (b) UV-Vis reflectance spectra of perovskite films with varying $\mathrm{f}-\mathrm{SiO}_{2}$ wt\% loadings. ${ }^{140}$
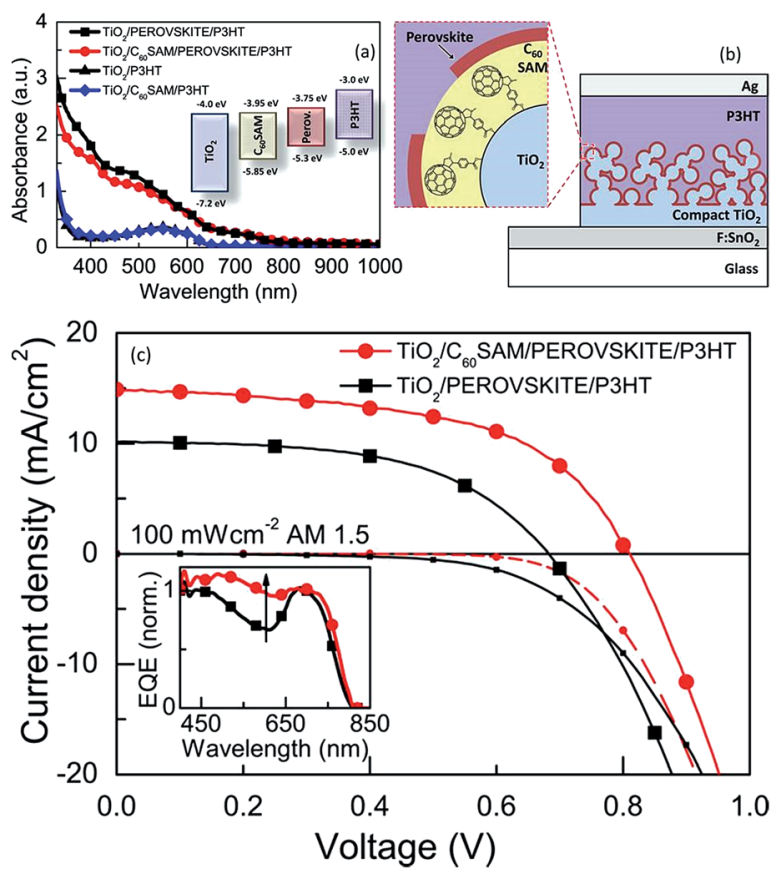

Fig. 30 (a) Absorption spectra of P3HT and perovskite films with and without $\mathrm{C}_{60} \mathrm{SAM}$ fullerene functionalization. The materials were cast on glass substrates which had been coated with a $600 \mathrm{~nm}$ thick $\mathrm{m}$ $\mathrm{TiO}_{2}$ layer. Inset: energy levels of the system components relative to vacuum. (b) Schematic of the device 4d. (c) Microstructure and morphology effect (c) $J-V$ characteristics taken under AM1.5 simulated sunlight (100 $\mathrm{mW} \mathrm{cm}^{-2}$ irradiance) and in the dark for devices with and without $\mathrm{C}_{60} \mathrm{SAM}$ fullerene functionalization. Inset: external quantum efficiencies (EQE) for the same devices. ${ }^{141}$

In this approach, $\mathrm{C}_{60} \mathrm{SAM}$ functionalized mesoporous $\mathrm{TiO}_{2}$ enhances both the absorption and the electron injection. It was observed that the contact between the perovskite and the planar n-type $\mathrm{TiO}_{2}$ charge collection layer was not effective for electron transfer. Modifying this contact with an organic electron-accepting fullerene self-assembled monolayer $\left(\mathrm{C}_{60^{-}}\right.$ SAM) modified $\mathrm{TiO}_{2}$, significantly enhanced the electron transfer. ${ }^{141}$ Most of the interlayer organic/polymer molecules passivate or inhibit the formation of trap states at the interface, on the $\mathrm{TiO}_{2}$ surface through the anchoring group. This results in reduction of the non-radiative recombination channels at this interface. ${ }^{142}$ Through electroluminescence (EL) studies, Wojciechowski et al. showed a 5/10-fold increase in the electroluminescence signal for a fullerene-modified sample compared with a standard cell, indicating that the non-radiative recombination at the heterojunction was reduced with the $\mathrm{C}_{60}-\mathrm{SAM}$ treatment. The observed increase in EL intensity also suggests that the functionalization led to a reduction of interface defect sites, either on the $\mathrm{TiO}_{2}$ or in the perovskite, which would otherwise cause non-radiative recombination of injected carriers. This is consistent with recent results by Q. Wang et al., who suggested that fullerene can passivate trap states in the perovskite itself. Using triple cathode buffer layers consisting of PCBM/C60/LiF, a PCE of up to $14.24 \%$ was achieved with excellent stability (Fig. 30). ${ }^{143}$ 
Growing interest in PSCs and increased knowledge on how to improve their efficiency by manipulating the microstructure, morphologies, doping, and device architecture has resulted in development of several techniques to fulfil these requirements. For example, several methods have been suggested to deposit ETM/ETL. The most common technique is spin coating of $\mathrm{m}$ $\mathrm{TiO}_{2}$. The thickness of $\mathrm{m}-\mathrm{TiO}_{2}$ can be controlled by the concentration of $\mathrm{m}-\mathrm{TiO}_{2}$ in ethanol solution in iso-propyl alcohols. This method has been found to be more reliable and easier than other techniques. Nanostructured ETM/ETL can be prepared by a hydrothermal method. Kim et al. observed PCE of more than $13 \%$ using $20 \mathrm{~nm}$ of ALD-deposited $\mathrm{TiO}_{2}$ on an ITO/PEN substrate. They reported that $20 \mathrm{~nm}$ ALD-deposited $\mathrm{a}-\mathrm{TiO}_{x}$ effectively collected the electron from the perovskite layer without mesoporous $\mathrm{TiO}_{2} \cdot{ }^{18}$ Wang et al. used nanocomposites of graphene and $\mathrm{TiO}_{2}$ nanoparticles to produce highly efficient ETL in PSC. They postulated that most of the electron density resides on the graphene and ensuing "depleted" $\mathrm{TiO}_{2}$ is contacting the perovskite will have a lower recombination rate with the holes in the perovskite because of reduced electron density in the $\mathrm{TiO}_{2}$, thus contributing to the increase in the photocurrent. ${ }^{\mathbf{1 4 4}}$

\section{Conclusions}

We have summarized and discussed recent developments in mesoscopic ETM-based organometallic halide perovskite-based solar cells. With extensive research and accumulated understanding, the unique physical and optoelectronic properties, pore filling, and surface coverage characteristics of mesoscopic organometallic halide perovskites have been explored and elucidated. This review also addressed the charge injection, charge retardation by implementing the doping in metal oxide NPs, and heterostructured core-shell nanoparticles. Dipoleinduced facile charge injection using thin polymer layers is also discussed. ETL/ETMs in PSCs are currently being intensively studied by many research groups around the world, producing a lot of promising results. Optimization of the following factors, (a) "scaffold" thickness and porosity modification, (b) interface/electrode engineering, (c) electron transport through the ETL/ETM, (d) doping, and (e) HTM adjustment are shown to effectively improve light harvesting in PSCs. Special design of ETLs and ETMs for efficient PSCs not exhibiting hysteresis in solution-processed devices is also discussed. To fabricate these porous scaffolds as well as the thin blocking layer, especially employed in state-of-the-art PSCs, the process of sintering at high temperatures is needed, which increases production cost and energy consumption, and also limits the possibility of fabricating large-area, flexible devices. Thus, in the future, developing low-temperature fabricated devices will be a promising direction and trend. Although great success in the photovoltaic field has been achieved for organometallic halide perovskites, the presence of reliance on heavy metals such as lead, the extremely high sensitivity of organometallic halide perovskites to elevated temperature and moisture, and the presence of significant hysteresis effects remain among the key limiting factors for practical applications of perovskite materials in the photovoltaic field.

\section{Notes and references}

1 K. D. Karlin, Prog. Inorg. Chem., 2007, vol. 48, DOI: 10.1002/ 9780470166499.

2 A. Kojima, K. Teshima, Y. Shirai and T. Miyasaka, J. Am. Chem. Soc., 2009, 131, 6050-6051.

3 Z. K. Tan, R. S. Moghaddam, M. L. Lai, P. Docampo, R. Higler, F. Deschler, M. Price, A. Sadhanala, L. M. Pazos, D. Credgington, F. Hanusch, T. Bein, H. J. Snaith and R. H. Friend, Nat. Nanotechnol., 2014, 9, 687-692.

4 Y. H. Kim, H. Cho, J. H. Heo, T. S. Kim, N. S. Myoung, C. L. Lee, S. H. Im and T. W. Lee, Adv. Mater., 2015, 27, 1248-1254.

5 H. R. Xia, J. Li, W. T. Sun and L. M. Peng, Chem. Commun., 2014, 50, 13695-13697.

6 L. Dou, Y. Yang, J. You, Z. Hong, W. H. Chang, G. Li and Y. Yang, Nat. Commun., 2014, 5, 5404.

7 Y. Lee, J. Kwon, E. Hwang, C. H. Ra, W. J. Yoo, J. H. Ahn, J. H. Park and J. H. Cho, Adv. Mater., 2015, 27, 41-46.

8 X. Hu, X. Zhang, L. Liang, J. Bao, S. Li, W. Yang and Y. Xie, Adv. Funct. Mater., 2014, 24, 7373-7380.

9 N. Akhtar, A. O. Polyakov, A. Aqeel, P. Gordiichuk, G. R. Blake, J. Baas, H. Amenitsch, A. Herrmann, P. Rudolf and T. T. M. Palstra, Small, 2014, 10, 4912-4919.

10 C. R. Carmona, O. Malinkiewicz, A. Soriano, G. M. Espallargas, A. Garcia, P. Reinecke, T. Kroyer, M. I. Dar, M. K. Nazeeruddin and H. J. Bolink, Energy Environ. Sci., 2014, 7, 994-997.

11 X. Wang, Z. Li, W. Xu, S. A. Kulkarni, S. K. Batabyal, S. Zhang, A. Cao and L. H. Wong, Nano Energy, 2015, 11, 728-735.

12 Y.-F. Chiang, J.-Y. Jeng, M.-H. Lee, S. R. Peng, P. Chen, T. F. Guo, T.-C. Wen, Y.-J. Hsu and C.-M. Hsu, Phys. Chem. Chem. Phys., 2014, 16, 6033-6040.

13 Y. Yang, J. You, Z. Hong, Q. Chen, M. Cai, T.-B. Song, C.-C. Chen, S. Lu, Y. Liu and H. Zhou, ACS Nano, 2014, 8, 1674-1680.

14 L. Qiu, J. Deng, X. Lu, Z. Yang and H. Peng, Angew. Chem., 2014, 53, 10425-10428.

15 J. W. Jung, S. T. Williams and A. K.-Y. Jen, RSC Adv., 2014, 4, 62971-62977.

16 P. Docampo, J. M. Ball, M. Darwich, G. E. Eperon and H. J. Snaith, Nat. Commun., 2013, 4, 2761.

17 M. H. Kumar, N. Yantara, S. Dharani, M. Graetzel, S. Mhaisalkar, P. P. Boix and N. Mathews, Chem. Commun., 2013, 49, 11089-11091.

18 B. J. Kim, D. H. Kim, Y. Y. Lee, H. W. Shin, G. S. Han, J. S. Hong, K. Mahmood, T. K. Ahn, Y. C. Joo, K. S. Hong, N.-G. Park, S. Lee and H. S Jung, Energy Environ. Sci., 2015, 8, 916-921.

19 J. L. Knutson and J. D. Martin, Inorg. Chem., 2005, 44, 46994705; T. Baikie, Y. Fang, J. M. Kadro, M. Schreyer, F. Wei, S. G. Mhaisalkar, M. Graetzel and T. J. White, J. Mater. Chem. A, 2013, 1, 5628-5641.

20 M. R. Filip and F. Giustino, Phys. Rev. B: Condens. Matter Mater. Phys., 2014, 90, 245145. 
21 S. Sourisseau, N. Louvain, W. Bi, N. Mercier, D. Rondeau, F. Boucher, J. Y. Buzaré and C. Legein, Chem. Mater, 2007, 19, 600-607.

22 L. Pedesseau, J. M. Jancu, A. Rolland, E. Deleporte and C. Katan, Opt. Quantum Electron., 2014, 46, 1225-1232.

23 N. J. Jeon, J. H. Noh, W. S. Yang, Y. C. Kim, S. Ryu, J. Seo and S. I. Seok, Nature, 2015, 517, 476-480.

24 N. J. Jeon, J. H. Noh, Y. C. Kim, W. S. Yang, S. Ryu and S. I. Seok, Nat. Mater., 2014, 13, 897-903.

25 S. D. Stranks, G. E. Eperon, G. Grancini, C. Menelaou, M. J. P. Alcocer, T. Leijtens, L. M. Herz, A. Petrozza and H. J. Snaith, Science, 2013, 342, 341-344.

26 G. Xing, N. Mathews, S. Sun, S. S. Lim, Y. M. Lam, M. Grätzel, S. Mhaisalkar and T. C. Sum, Science, 2013, 342, 344-347.

27 Q. Dong, Y. Fang, Y. Shao, P. Mulligan, J. Qiu, L. Cao and J. Huang, Science, 2015, 347(6225), 967-970.

28 S. Bai, Z. Wu, X. Wu, Y. Jin, N. Zhao, Z. Chen, Q. Mei, X. Wang, Z. Ye, T. Song, R. Liu, S.-T. Lee and B. Sun, Nano Res., 2014, 7, 1749-1758.

29 J. Bisquert, L. Bertoluzzi, I. Mora-Sero and G. GarciaBelmonte, J. Phys. Chem. C, 2014, 118, 18983-18991.

30 Research Cell Efficiency Records, NREL, National Renewable Energy Data, 2015, http://www.nrel.gov/ncpv/.

31 G. Giorgi, J. I. Fujisawa, H. Segawa, K. Yamashita and J. Phys, Chem. Lett., 2013, 4, 4213-4216.

32 J. Feng and B. Xiao, J. Phys. Chem. C, 2014, 118, 1965519660.

33 H. S. Jung and N. G. Park, Small, 2015, 11, 10-25.

34 K. Wang, C. Liu, P. Du, J. Zheng and X. Gong, Energy Environ. Sci., 2015, 8, 1245-1255.

35 C. Liu, K. Wang, P. Du, C. Yi, T. Meng and X. Gong, Adv. Eng. Mater., 2015, 5, 1402024.

36 Y. Liu, Z. Hong, Q. Chen, W. Chang, H. Zhou, T. B. Song, E. Young, Y. Yang, J. You, G. Li and Y. Yang, Nano Lett., 2015, 15, 662-668.

37 W. Wang, J. Yuan, G. Shi, X. Zhu, S. Shi, Z. Liu, L. Han, H. Q. Wang and W. Ma, ACS Appl. Mater. Interfaces, 2015, 7, 3994-3999.

38 D. X. Yuan, A. Gorka, M. F. Xu, Z. K. Wang and L. S. Liao, Phys. Chem. Chem. Phys., 2015, 17, 19745-19750.

39 Y. Bai, H. Yu, Z. Zhu, K. Jiang, T. Zhang, N. Zhao, S. Yang and H. Yan, J. Mater. Chem. A, 2015, 3, 9098-9102.

40 J. H. Heo, H. J. Han, D. Kim, T. K. Ahn and S. H. Im, Energy Environ. Sci., 2015, 8, 1602-1608.

41 T. Leijtens, B. Lauber, G. E. Eperon, S. D. Stranks and H. J. Snaith, J. Phys. Chem. Lett., 2014, 5, 1096-1102.

42 Q. Jiang, X. Sheng, Y. Li, X. Feng and T. Xu, Chem. Commun., 2014, 50, 14720-14723.

43 J. Qiu, Y. Qiu, K. Yan, M. Zhong, C. Mu, H. Yan and S. Yang, Nanoscale, 2013, 5, 3245-3248.

44 H. S. Kim, J. W. Lee, N. Yantara, P. P. Boix, S. A. Kulkarni, S. Mhaisalkar, M. Grätzel and N. G. Park, Nano Lett., 2013, 13, 2412-2417.

45 Y. Yu, J. Li, D. Geng, J. Wang, L. Zhang, T. L. Andrew, M. S. Arnold and X. Wang, ACS Nano, 2015, 9, 564-572.
46 D. Y. Son, J. H. Im, H. S. Kim and N. G. Park, J. Phys. Chem. C, 2014, 118, 16567-16573.

47 K. Mahmood, B. S. Swain, A. R. Kirmani and A. Amassian, J. Mater. Chem. A, 2015, 3, 9051-9057.

48 L. Liang, Z. Huang, L. Cai, W. Chen, B. Wang, K. Chen, H. Bai, Q. Tian and B. Fan, ACS Appl. Mater. Interfaces, 2014, 6, 20585-20589.

49 L. Etgar, P. Gao, Z. Xue, Q. Peng, A. K. Chandiran, B. Liu, M. K. Nazeeruddin and M. Grätzel, J. Am. Chem. Soc., 2012, 134, 17396-17399.

50 S. Dharani, H. K. Mulmudi, N. Yantara, P. T. T. Trang, N. G. Park, M. Graetzel, S. Mhaisalkar, N. Mathews and P. P. Boix, Nanoscale, 2014, 6, 1675-1679.

51 X. Zhang, Z. Bao, X. Tao, H. Sun, W. Chen and X. Zhou, RSC Adv., 2014, 4, 64001-64005.

52 K. Manseki, T. Ikeya, A. Tamura, T. Ban, T. Sugiura and T. Yoshida, RSC Adv., 2014, 4, 9652-9655.

53 H. S. Kim, C. R. Lee, J. H. Im, K. B. Lee, T. Moehl, A. Marchioro, S. J. Moon, R. Humphry-Baker, J. H. Yum, J. E. Moser, M. Grätzel and N. G. Park, Sci. Rep., 2012, 2, 591. 54 Y. Wu, X. Yang, H. Chen, K. Zhang, C. Qin, J. Liu, W. Peng, A. Islam, E. Bi, F. Ye, M. Yin, P. Zhang and L. Han, Appl. Phys. Express, 2014, 7, 052301.

55 K. C. Wang, P. S. Shen, M. H. Li, S. Chen, M. W. Lin, P. Chen and T. F. Guo, ACS Appl. Mater. Interfaces, 2014, 6, 1185111858.

56 A. S. Subbiah, A. Halder, S. Ghosh, N. Mahuli, G. Hodes and S. K. Sarkar, J. Phys. Chem. Lett., 2014, 5, 1748-1753.

57 E. Edri, S. Kirmayer, A. Henning, S. Mukhopadhyay, K. Gartsman, Y. Rosenwaks, G. Hodes and D. Cahen, Nano Lett., 2014, 14, 1000-1004.

58 S. Gamliela and L. Etgar, RSC Adv., 2014, 4, 29012-29021.

59 T. C. Sum and N. Mathews, Energy Environ. Sci., 2014, 7, 2518-2534.

60 W. H. Zhang and B. Cai, Chin. Sci. Bull., 2014, 59, 20922101.

61 J. Yana and B. R. Saunders, RSC Adv., 2014, 4, 43286-43314.

62 B. Wang, X. Xiao and T. Chen, Nanoscale, 2014, 6, 1228712297.

63 M. A. Green, A. Ho-Baillie and H. J. Snaith, Nat. Photonics, 2014, 8, 506-514.

64 P. Gao, M. Grätzel and M. K. Nazeeruddin, Energy Environ. Sci., 2014, 7, 2448-2463.

65 P. P. Boix, K. Nonomura, N. Mathews and S. G. Mhaisalkar, Mater. Today, 2014, 17.

66 S. Luo and W. A. Daoud, J. Mater. Chem. A, 2015, 3, 89929010.

67 T. Minemoto and M. Murata, J. Appl. Phys., 2014, 116, 054505.

68 T. J. Savenije, C. S. Ponseca, L. Kunneman, M. Abdellah, K. Zheng, Y. Tian, Q. Zhu and J. Phys, Chem. Lett., 2014, 5, 2189-2194.

69 D. Nanova, A. K. Kast, M. Pfannmöller, C. Müller, L. Veith, I. Wacker, M. Agari, W. Hermes, P. Erk, W. Kowalsky, R. R. Schröder and R. Lovrinčić, Nano Lett., 2014, 14, 2735-2740. 
70 A. Yella, L. P. Heiniger, P. Gao, M. K. Nazeeruddin and M. Grätzel, Nano Lett., 2014, 14, 2591-2596.

71 H. Zhou, Q. Chen, G. Li, S. Luo, T. B. Song, H. S. Duan, Z. Hong, J. You, Y. Liu and Y. Yang, Science, 2014, 345, 542.

72 A. K. Chandiran, M. Abdi-Jalebi, A. Yella, M. I. Dar, C. Yi, S. A. Shivashankar, M. K. Nazeeruddin and M. Grätzel, Nano Lett., 2014, 14, 1190-1195.

73 G. S. Han, H. S. Chung, B. J. Kim, D. H. Kim, J. W. Lee, B. S. Swain, K. Mahmood, J. S. Yoo, N. G. Park, J. H. Lee and H. S. Jung, J. Mater. Chem. A, 2015.

74 K. Mahmood, B. S. Swain, A. R. Kirmani and A. Amassian, J. Mater. Chem. A, 2015, 3, 9051-9057.

75 T. Leijtens, G. E. Eperon, S. Pathak, A. Abate, M. M. Lee and H. J. Snaith, Nat. Commun., 2013, 4, 2885.

76 G. Boschloo and D. Fitzmaurice, J. Phys. Chem. B, 1999, 103, 2228-2231.

77 S. D. Sung, D. P. Ojha, J. S. You, J. Lee, J. Kim and W. I. Lee, Nanoscale, 2015, 7, 8898.

78 L. Wang, W. Fu, Z. Gu, C. Fan, X. Yang, H. Li and H. Chen, J. Mater. Chem. C, 2014, 2, 9087-9090.

79 J. Song, E. Zheng, J. Bian, X.-F. Wang, W. Tian, Y. Sanehirac and T. Miyasaka, J. Mater. Chem. A, 2015, 3, 10837.

80 J.-W. Lee, S. H. Lee, H.-S. Ko, J. Kwon, J. H. Park, S. M. Kang, N. Ahn, M. Choi, J. K. Kim and N.-G. Park, J. Mater. Chem. A, 2015, 3, 9179-9186.

81 S. H. Hwang, J. Roh, J. Lee, J. Ryu, J. Yun and J. S. Jang, J. Mater. Chem. A, 2014, 2, 16429-16433.

82 G. Niu, W. Li, F. Meng, L. Wang, H. Dong and Y. Qiu, J. Mater. Chem. A, 2014, 2, 705-710.

83 X. Dong, X. Fang, M. Lv, B. Lin, S. Zhang, J. Ding and N. Yuan, J. Mater. Chem. A, 2015, 3, 5360.

84 D. Bi, S. J. Moon, L. Haggman, G. Boschloo, L. Yang, E. M. J. Johansson, M. K. Nazeeruddin, M. Gratzel and A. Hagfeldt, RSC Adv., 2013, 3, 18762.

85 Q. Wang, Y. Shao, Q. Dong, Z. Xiao, Y. Yuan and J. Huang, Energy Environ. Sci., 2014, 7, 2359-2365.

86 C. H. Chiang, Z. L. Tseng and C. G. Wu, J. Mater. Chem. A, 2014, 2, 15897-15903.

87 O. Malinkiewicz, A. Yella, Y. H. Lee, G. M. Espallargas, M. Graetzel, M. K. Nazeeruddin and H. J. Bolink, Nat. Photonics, 2014, 8, 128-132.

88 J. You, Z. Hong, Y. Yang, Q. Chen, M. Cai, T. B. Song, C. C. Chen, S. Lu, Y. Liu, H. Zhou and Y. Yang, ACS Nano, 2014, 8, 1674-1680.

89 J. Seo, S. Park, Y. C. Kim, N. J. Jeon, J. H. Noh, S. C. Yoon and S. I. Seok, Energy Environ. Sci., 2014, 7, 2642-2646.

90 L. C. Chen, J.-C. Chen, C.-C. Chen and C. G. Wu, Nanoscale Res. Lett., 2015, 10, 312-3016.

91 J. Y. Jeng, K. C. Chen, T. Y. Chiang, P. Y. Lin, T. D. Tsai, Y. C. Chang, T. F. Guo, P. Chen, T. C. Wen and Y. J. Hsu, Adv. Mater., 2014, 26, 4107-4113.

92 X. Liu, M. Lei, Y. Zhou, B. Song and Y. Li, Appl. Phys. Lett., 2015, 107, 063901.

93 A. T. Barrows, A. J. Pearson, C. K. Kwak, A. D. F. Dunbar, A. R. Buckley and D. G. Lidzey, Energy Environ. Sci., 2014, 7, 2944-2950.
94 F. Xia, Q. Wu, P. Zhou, Y. Li, X. Chen, Q. Liu, J. Zhu, S. Dai, Y. Lu and S. Yang, ACS Appl. Mater. Interfaces, 2015, 7, 13659-13665.

95 C. Li, F. Wang, J. Xu, J. Yao, B. Zhang, C. Zhang, M. Xiao, S. Dai, Y. Li and Z. Tan, Nanoscale, 2015, 7, 9771-9778.

96 W. Ke, G. Fang, J. Wan, H. Tao, Q. Liu, L. Xiong, P. Qin, J. Wang, H. Lei, G. Yang, M. Qin, X. Zhao and Y. Yan, Nat. Commun., 2015, 6, 6700.

97 S. Ameen, M. S. Akhtar, H.-K. Seo, M. K. Nazeeruddin and H. S. Shin, Dalton Trans., 2015, 44, 6439.

98 A. K. Chandiran, A. Yella, M. T. Mayer, P. Gao, M. K. Nazeeruddin and M. Grätzel, Adv. Mater., 2014, 26, 4309-4312.

99 G. S. Han, S. W. Lee, J. H. Noh, H. S. Chung, J. H. Park, B. S. Swain, J. H. Im, N. G. Park and H. S. Jung, Nanoscale, 2014, 6, 6127.

100 S. M. Yong, T. Nikolay, B. T. Ahn and D. K. Kim, J. Alloys Compd., 2013, 547, 113-117.

101 H. Zheng, Y. Tachibana and K. Kalantar-zadeh, Langmuir, 2010, 26, 19148-19152.

102 K. Wang, Y. Shi, Q. Dong, Y. Li, S. Wang, X. Yu, M. Wu and T. Ma, J. Phys. Chem. Lett., 2015, 6, 755-759.

103 W. Z. Li, J. L. Li, L. D. Wang, G. D. Niu, R. Gao and Y. Qiu, J. Mater. Chem. A, 2013, 1, 11735-11740.

104 X. Guo, H. Dong, W. Li, N. Li and L. Wang, ChemPhysChem, 2015, 16, 1727-1732.

105 P. Qin, A. L. Domanski, A. K. Chandiran, R. Berger, H. J. Butt, M. I. Dar, T. Moehl, N. Tetreault, P. Gao, S. Ahmad, M. K. Nazeeruddin and M. Grätzel, Nanoscale, 2014, 6, 1508-1514.

106 K. Mahmood, B. S. Swain and H. S. Jung, Nanoscale, 2014, 6, 9127-9138.

107 K. Mahmood, B. S. Swain and A. Amassian, Adv. Eng. Mater., 2015, 5, 1500568.

108 Y. Xiao, G. Han, Y. Li, M. Li and J. Wu, J. Mater. Chem. A, 2014, 2, 16856.

109 J. Dong, Y. Zhao, J. Shi, H. Wei, J. Xiao, X. Xu, J. Luo, J. Xu, D. Li, Y. Luo and Q. Meng, Chem. Commun., 2014.

110 K. Mahmood, B. S. Swain and A. Amassian, Adv. Mater., 2015, 27, 2859-2865.

111 D. H. Kim, G. S. Han, W. M. Seong, J. W. Lee, B. J. Kim, N. G. Park, K. S. Hong, S. W. Lee and H. S. Jung, ChemSusChem, 2015, 14, 2392-2398.

112 V. Roiati, E. Mosconi, A. Listorti, S. Colella, G. Gigli and F. D. Angelis, Nano Lett., 2014, 14, 2168-2174.

113 S. Colella, E. Mosconi, P. Fedeli, A. Listorti, F. Gazza, F. Orlandi, P. Ferro, T. Besagni, A. Rizzo, G. Calestani, G. Gigli, F. D. Angelis and R. Mosca, Chem. Mater., 2013, 25, 4613-4618.

114 P. Docampo, F. C. Hanusch, S. D. Stranks, M. Döblinger, J. M. Feckl, M. Ehrensperger, N. K. Minar, M. B. Johnston, H. J. Snaith and T. Bein, Adv. Energy Mater., 2014, 4, 1400355.

115 R. Sheng, A. H. Baillie, S. Huang, S. Chen, X. Wen, X. Hao and M. A. Green, J. Phys. Chem. C, 2015, 119, 3545-3549. 
116 W. Ke, G. Fang, J. Wang, P. Qin, H. Tao, H. Lei, Q. Liu, X. Dai and X. Z. Zhao, ACS Appl. Mater. Interfaces, 2014, 6, 15959-15965.

117 M. I. Dar, F. J. Ramos, Z. Xue, B. Liu, S. Ahmad, S. A. Shivashankar, M. Khaja Nazeeruddin and M. Grätzel, Chem. Mater., 2014, 26, 4675-4678.

118 L. S. Oh, D. H. Kim, J. A. Lee, S. S. Shin, J. W. Lee, I. J. Park, M. J. Ko, N. G. Park, S. G. Pyo, K. S. Hong and J. Y. Kim, J. Phys. Chem. C, 2014, 118, 22991-22994.

119 S. S. Shin, W. S. Yang, J. H. Noh, J. H. Suk, N. J. Jeon, J. H. Park, J. S. Kim, W. M. Seong and S. I. Seok, Nat. Commun., 2015, 6, 7410, DOI: 10.1038/ncomms8410.

120 S. S. Mali, C. S. Shim and C. K. Hong, Sci. Rep., 2015, 5, 11424.

121 H.-H. Wang, Q. Chen, H. Zhou, L. Song, Z. S. Louis, N. D. Marco, Y. Fang, P. Sun, T. B. Song, H. Chen and Y. Yang, J. Mater. Chem. A, 2015, 3, 9108.

122 Y. C. Shih, L. Y. Wang, H. C. Hsieha and K. F. Lin, J. Mater. Chem. A, 2015, 3, 9133-9136.

123 J. Kim, G. Kim, T. K. Kim, S. Kwon, H. Baek, J. Lee, S. H. Lee, H. Kang and K. Lee, J. Mater. Chem. A, 2014, 2, 1729117296.

124 C. Liu, K. Wang, P. Du, C. Yi, T. Meng and X. Gong, Adv. Energy Mater., 2015, 1402024.

125 C. Tao, S. Neutzner, L. Colella, S. Marras, A. R. S. Kandada, M. Gandini, M. D. Bastiani, G. Pace, L. Manna, M. Caironi, C. Bertarelli and A. Petrozza, Energy Environ. Sci., 2015, 8, 2365-2370.

126 M. M. Lee, J. Teuscher, T. Miyasaka, T. N. Murakami and H. J. Snaith, Science, 2012, 338, 643-647.

127 S. Ryu, J. H. Noh, N. J. Jeon, Y. C. Kim, W. S. Yang, J. W. Seo and S. I. Seok, Energy Environ. Sci., 2014, 7, 2614-2618.

128 J. Kim, G. Kim, T. K. Kim, S. Kwon, H. Baek, J. Lee, S. H. Lee, H. Kang and K. Lee, J. Mater. Chem. A, 2014, 2, 1729117296.

129 Z. Yuan, Z. Wu, S. Bai, Z. Xia, W. Xu, T. Song, H. Wu, L. Xu, J. Si, Y. Jin and B. Sun, Adv. Energy Mater., 2015, 5, 1500038.

130 Z. Lu, X. Pan, Y. Ma, Y. Li, L. Zheng, D. Zhang, Q. Xu, Z. Chen, S. Wang, B. Qu, F. Liu, Y. Huang, L. Xiao and Q. Gong, $R S C A d v$. , 2015, 5, 11175.

131 H. Azimi, T. Ameri, H. Zhang, Y. Hou, C. O. R. Quiroz, J. Min, M. Hu, Z. G. Zhang, T. Przybilla, G. J. Matt, E. Spiecker, Y. Li and C. J. Brabec, Adv. Energy Mater., 2015, 5, 1401692.

132 K. Wang, C. Liu, P. Du, J. Zheng and X. Gong, Energy Environ. Sci., 2015, 8, 1245.

133 C. Zuo and L. Ding, J. Mater. Chem. A, 2015, 3, 9063.
134 K. Sun, J. Chang, F. H. Isikgor, P. Li and J. Ouyang, Nanoscale, 2015, 7, 896.

135 K. Sun, B. M. Zhao, A. Kumar, K. Y. Zeng and J. Y. Ouyang, ACS Appl. Mater. Interfaces, 2012, 4, 2009.

136 K. Sun, B. Zhao, V. Murugesan, A. Kumar, K. Zeng, J. Subbiah, W. W. H. Wong, D. J. Jones and J. Ouyang, J. Mater. Chem., 2012, 22, 24155.

137 Y. C. Shih, L. Y. Wang, H. C. Hsieh and K. F. Lin, J. Mater. Chem. A, 2015, 3, 9133.

138 S. Ryu, J. Seo, S. S. Shin, Y. C. Kim, N. J. Jeon, J. H. Noh and S. I. Seok, J. Mater. Chem. A, 2015, 3, 3271.

139 A. Sarkar, N. J. Jeon, J. H. Noh and S. I. Seok, J. Phys. Chem. C, 2014, 118, 16688-16693.

140 M. J. Carnie, C. Charbonneau, M. L. Davies, B. O'Regan, A. A. Worsleya and T. M. Watson, J. Mater. Chem. A, 2014, 2, 17077-17084.

141 A. Abrusci, S. D. Stranks, P. Docampo, H. L. Yip, A. K. Y. Jen and H. J. Snaith, Nano Lett., 2013, 13, 3124-3128.

142 K. Wojciechowski, S. D. Stranks, A. Abate, G. Sadoughi, A. Sadhanala, N. Kopidakis, G. Rumbles, C. Z. Li, R. H. Friend, A. K.-Y. Jen and H. J. Snaith, ACS Nano, 2014, 8, 12701-12709.

143 X. Liu, H. Yu, L. Yan, Q. Dong, Q. Wan, Y. Zhou, B. Song and Y. Li, ACS Appl. Mater. Interfaces, 2015, 7, 6230-6237.

144 J. T.-W. Wang, J. M. Ball, E. M. Barea, A. Abate, J. A. A. Webber, J. Huang, M. Saliba, I. M. Sero, J. Bisquert, H. J. Snaith and R. J. Nicholas, Nano Lett., 2014, 14, 724-730.

145 J. Min, Z. G. Zhang, Y. Hou, C. O. R. Quiroz, T. Przybilla, C. Bronnbauer, F. Guo, K. Forberich, H. Azimi, T. Ameri, E. Spiecker, Y. Li and C. J. Brabec, Chem. Mater., 2015, 27, 227-234.

146 Q. Xue, Z. Hu, J. Liu, J. Lin, C. Sun, Z. Chen, C. Duan, J. Wang, C. Liao, W. M. Lau, F. Huang, H. L. Yip and Y. Cao, J. Mater. Chem. A, 2014, 2, 19598.

147 W. Ke, G. Fang, Q. Liu, L. Xiong, P. Qin, H. Tao, J. Wang, H. Lei, B. Li, J. Wan, G. Yang and Y. Yan, J. Am. Chem. Soc., 2015, 137, 6730-6733.

148 Q. Jiang, L. Zhang, H. Wang, X. Yang, J. Meng, H. Liu, Z. Yin, J. Wu, X. Zhang and J. You, Nat. Energy, 2016, 2, 16177.

149 E. H. Anaraki, A. Kermanpur, L. Steier, K. Domanski, T. Matsui, W. Tress, M. Saliba, A. Abate, M. Grä, A. Hagfeldt and J.-P. Correa-Baena, Energy Environ. Sci., 2016, 3128, 3128-3134.

150 G. Yang, C. Wang, H. Lei, X. Zheng, P. Qin, L. Xiong, X. Zhao, Y. Yan and G. Fang, J. Mater. Chem. A, 2017, 5, 1658-1666. 